Article

\title{
Cosmic Evolutionary Philosophy and a Dialectical Approach to Technological Singularity
}

\section{Cadell Last}

Evolution, Cognition, and Complexity (ECCO) group, Global Brain Institute; B-1160 Brussels, Belgium; cadell.last@gmail.com

Received: 13 February 2018; Accepted: 4 April 2018; Published: 5 April 2018

\begin{abstract}
The anticipated next stage of human organization is often described by futurists as a global technological singularity. This next stage of complex organization is hypothesized to be actualized by scientific-technic knowledge networks. However, the general consequences of this process for the meaning of human existence are unknown. Here, it is argued that cosmic evolutionary philosophy is a useful worldview for grounding an understanding of the potential nature of this futures event. In the cosmic evolutionary philosophy, reality is conceptualized locally as a universal dynamic of emergent evolving relations. This universal dynamic is structured by a singular astrophysical origin and an organizational progress from sub-atomic particles to global civilization mediated by qualitative phase transitions. From this theoretical ground, we attempt to understand the next stage of universal dynamics in terms of the motion of general ideation attempting to actualize higher unity. In this way, we approach technological singularity dialectically as an event caused by ideational transformations and mediated by an emergent intersubjective objectivity. From these speculations, a historically-engaged perspective on the nature of human consciousness is articulated where the truth of reality as an emergent unity depends on the collective action of a multiplicity of human observers.
\end{abstract}

Keywords: futures; technological singularity; philosophy; cosmic evolution; anthropology

\section{Global Technological Singularity}

Scientific networks constructed by human psychosocial processes have made measurable progress in understanding the natural world analytically through the tools of empirical observation and the methods of reduction and fragmentation. In these efforts, reduction refers to the practice of understanding nature by isolating particular phenomena in nature and analyzing its constituent parts like particles, molecules, and organisms [1]. The logic of reductionism has led to fragmentation of natural analysis into fields and sub-fields and sub-sub-fields focusing on ever more specified parts within the wider whole like physics, chemistry, and biology [2]. This dynamic analytic process is necessary for certain forms of understanding nature. For example, fields as diverse as M-theory in particle physics [3], or artificial intelligence in cognitive science [4], or genetic engineering in biology [5], could not exist without the tools of empirical observation becoming channeled through methods of reduction and fragmentation.

However, there is an emerging intellectual desire and social necessity in the philosophy of science and in the sciences of humanity to understand the historical dialectic consequences of scientific networks in relation to nature and humanity as a totality. This desire and necessity is due to an increasingly unpredictable, uncertain, and chaotic future horizon of becoming [6]. In short, scientific reduction and fragmentation allow us to understand diverse objective phenomena, but is unable to help us understand the emergent holistic consequence of this understanding for subjectivity. For example, throughout the history of modern science the human existential position and relation to nature has become de-centered from the classical philosophical immediacy of being [7], and also the traditional 
religious affirmation of God [8]. These de-centerings are often framed in cosmic terms (e.g., Copernican heliocentrism), biological terms (e.g., Darwinian selectionism), and psychological terms (e.g., Freudian unconscious) [9]. Such symbolic movements generated by scientific knowledge leave us devoid of absolute value, consequently producing fundamental metaphysical crises of human meaning vis-à-vis being itself [10].

In short, metaphysical de-centerings caused by scientific networks have allowed for deeper reductionist understanding of nature, like understanding the nature of solar systems and galaxies, the nature of evolution of living forms, and the nature of unconscious dreams and desires. However, this knowledge has simultaneously resulted in a broken and incoherent visions of holistic totality in relation to classical or traditional metaphysics. If we define humanity by the peculiar nature of our self-consciousness (awareness of being, reflection on being), then philosophical understandings of totality situated humanity in relation to either ideality in a transcendental superspace or a historical superspace as attractor [11]. However, in our contemporary age dominant conceptions of totality often become grounded in scientific materialist conceptions of cosmic or sub-atomic scale. In these visions of totality self-consciousness appears without experiential and transcendent aims of higher significance. We are frequently presented with narratives suggesting that the cosmos only has an inhuman aim of heat death leading to universal void, that biology has the inhuman aim of fitness maximization leading to endless living form replication, and that our own minds have a mysterious inhuman aim within related to unconscious drives and repetitions. From this understanding of totality notions of transcendent or historical ideality become difficult to convincingly substantiate on the terms of the critique of reason.

In this way the closed and complete worlds of classical or traditional metaphysics structured around the central importance of our self-conscious experience (on Earth) and its connection with divine transcendence (in Heaven) have been severed with the thought tools of Cartesian doubt and Kantian criticism [12]. The Cartesian cogito introduced the world to the centrality of rational thought as self-certainty of being, and Kantian transcendentals introduced the world to the a priori frame structuring being. Both philosophical tools prevent any connection in real knowledge to a closed and complete 'other world' capable of absolutely centering our being. This gives way for the growing chaos and uncertainty of the open and incomplete worlds of modern rationalism, where the central place of a fundamental ideal truth for human beings has no place outside of its own ego-centric bubble of illusion. In this frame ultimate or absolute existential meaning is replaced with a type of ultimate or absolute nihilism of being surrounded on all sides by forces working against our own interests. However, this situation grows more complex when we consider the mystery of the consequences of scientific epistemology in its broadest context of universal history [13]. To be specific the activity of scientific networks grounded in conceptual reduction and fragmentation can be logically extrapolated towards a futures horizon of a global technological singularity [14].

The notion of technological singularity driven by scientific networks actualizing artificial intelligence, genetic engineering, and quantum computing (for example) challenges theorists to think a fundamental impossibility of thought. This impossibility for thought is ultimately a qualitative phase transition representing a level of existence beyond our mental or ideational capability to meaningfully abstract. Thus, from the perspective of the human mind the technological singularity represents a type of infinity since it could involve the emergence of a phenomenal realm of higher level perception, thought, and communication, potentially in higher dimensional geometries than the three dimensional geometries (plus time) that fundamentally characterize and constrain human experience and aims. In terms of analytic mechanisms the most frequently deployed conjectures for the actual realization of such an event include artificial general intelligence (AGI) or human intelligence amplification (IA) [15-17].

In terms of scientific theory predictions for the emergence of a technological singularity are based on extrapolation models of exponential computational evolution. These models were originally founded on Moore's Law [18,19], and are currently often based on the 'Law of Accelerating Returns' 
(LOAR) [20,21]. Moore's law and LOAR suggest that in terms of pure computational capacity the total cognitive capacities of the human species will be surpassed before mid-century. This is why extrapolations of this process are represented with attractive metaphors from mathematics and physics of an approaching 'event horizon' towards an 'other side' of being [22]. Currently there is no coherent scientific model that helps us to describe the actualization of embodied superintelligence (in whatever form it takes) and the ontological effects of its higher order cognitive force. In other words, what will a civilization with such high levels of computing power be actualizing and how can we theoretically approach such phenomena? [23].

Thus the futures horizon of technological singularity signifies an immanent actuality of a post-human world where our own modernist social systems structured by reason and science give rise to a suite of technological possibilities that undermine both human existence and transcendence [24]. From the proper historical context the technological singularity may well represent yet another scientific de-centering where humanity's fundamental social and historical mode of being itself appears with an uncontrollable inhuman aim immanent to our nature $[25,26]$. In this frame social systems as symbolic networks of communication, here in the form of reason and science, overdetermine the highest experiential and emotional interests of humans themselves (self-consciousness) in favor of their own unbounded and unconscious propagation [27].

In popular discourse these issues of our uncontrollable social and historical modes of being are generally framed as part of the Anthropocene [28]. The Anthropocene signifies the fact that scientific epistemology and general human presence is both increasingly powerful and increasingly unpredictable in its ontological consequences [29]. However, in this context technologically mediated issues of global warming and economic inequality appear insignificant in comparison to the possibility of post-human systems of machinic superintelligence [21]. Are these processes evolutionarily determined to eliminate possibilities of human experience and transcendence [30,31], or is it possible to gain control of these social and historical modes of being and direct them towards actualizing desires of concern for human experience and emotion? [32,33] In either context, how can we make sense of totality in relation to the truth of nature and humanity as an integrated whole? (Table 1).

Table 1. Potential large-scale singularity consequences for self-consciousness. The radical unknown and unpredictable future horizon of human becoming in relationship to scientific advancements in robotics, artificial intelligence, nanotechnology, genetics, and other possible actualizations is becoming a growing and central concern of human evolution, possibly requiring dialectical analysis. In this dialectical analysis the internal horizon of negative-affirmative ideality structures becoming around a center singularity.

\begin{tabular}{cc}
\hline Pathway. & Phenomena \\
\hline Artificial Intelligence (AI) Scenario & $\begin{array}{c}\text { Super-intelligent/conscious technological systems replace } \\
\text { biocultural humans }\end{array}$ \\
\hline Intelligence Amplification (IA) Scenario & $\begin{array}{c}\text { Biocultural humans transform their being with technological } \\
\text { systems becoming trans/post-humans }\end{array}$ \\
\hline AI-IA Scenario & Complex interrelation of both organizational processes occur \\
\hline
\end{tabular}

When thinking about totality inclusive of a possible technological singularity we must first situate it in its historical ideality because its archetypal structure is not distinct from many other ideational structures internal to the symbolic order. In fact, the singularity, in terms of its attractive intensities and qualities of higher mentality, may be conceptualized as a techno-scientific representation that recaptures the metaphorical structure of many foundational religious traditions [34]. In particular this techno-scientific singularity thought structure resembles the thought structure of Western Abrahamic traditions like Judaism, Christianity, and Islam which formed the metaphysical ground for historical civilization before scientific modernity [35]. For Western religious traditions fundamental metaphysics natural being as given to self-consciousness is conceived of as insufficient or lacking due to fundamental 
experiential coordinates of morality, finitude, suffering, etc., and can only be remedied or reconciled by a future qualitative phase transition that restructures the relation between natural being and self-consciousness. Of course, in predominantly ancient religious narratives and value structures such a qualitative phase transition occurs via death or resurrection where the disembodied soul escapes the constraints of the world and enters into the sublime gates of an eternal ideality destined to enjoy spiritual immortality with God [36].

Here the principal difference between the historical religious conceptions of metaphysical singularity and the technological singularity is that technological singularity theorists ground their approach towards an immanent qualitative phase transition for thought in both secular and evolutionary terms that can ultimately be traced to the origin of scientific thought itself $[37,38]$. There are two frequently deployed analogies from cosmic evolution to describe this future. The first analogy is the transition between simple chemical processes and complex cellular biology. This process in chemistry and biology is referred to as abiogenesis [39], and is often associated with the emergence of life, and sometimes also mind [40]. The second analogy is the transition between biological great apes and biocultural human tribes. This process in anthropology is often associated with the emergence of self-consciousness and language [41], and in theology and philosophy often associated with the spiritualization of the cosmos with a telos repetitively aiming for reconciliation of natural being [42,43]. These past secular events of the emergence of biology and language are evoked as relevant for future cognitive process in order to communicate the fact that the emergence of a previously non-existent evolutionary potentiality has actually occurred before over big historical time [44].

\section{Cosmic Evolutionary Philosophy}

In order to approach questions of totality today perhaps we should first consider utilizing the philosophical worldview of cosmic evolution. This worldview has been most frequently deployed for the tasks of both articulating notions of technological singularity [45] and situating human development in a cosmic context [46]. The cosmic evolutionary worldview attempts to build a philosophy that can approach an integrated holistic view of totality as opposed to the fragmented reductionist view [47] (Figure 1). Thus, in contrast to the approaches of reduction and fragmentation the cosmic evolutionary approach focuses on a holistic integration of all phenomenon as unified in which totality is analyzed from the beginning of known processual dynamics to the present moment $[45,48]$.

In this view we cannot understand totality without explaining the evolution of all networked phenomena on all scales of reality [49]. For example, instead of separating the world of physics which focuses on particle interactions and fields of force, and the world of chemistry which focuses on chemical interactions and autocatalytic cycles; a holistic and integrated view focuses on understanding the shared dynamic processes that connect the world of physics and the world of chemistry in an emergent multi-level hierarchal interaction [50-52]. The most recent attempts to develop holistic and integrated general theories of fundamental importance can be found in theories of self-organization that emphasize the spontaneous emergence of complex order from local interactions [53,54].

Thus cosmic evolutionary theory may be usefully applied in order to integrate an analysis capable of understanding the futures horizon of technological singularity where we predict an emergent order from the spontaneous local interactions of scientific networks internal to general society [55]. In this evolutionary philosophy human beings (and life and mind in general) can be meaningfully situated within the totality of cosmic processes of a multi-level hierarchal interaction, as opposed to being de-centered by multiple perspectival shifts (i.e., Copernicus, Darwin, Freud) internal to reductionist and fragmented science [56]. For example, in the cosmic evolutionary worldview the astrophysical singularity origin of the universe which gave rise to matter-energy and spacetime is not only an event that can be framed and resolved by quantum cosmology [57], but also an event that can and may need to be connected historically through dynamic processes of change that are giving rise to an emergent global civilization in the 21st Century [6] (Figure 2). 


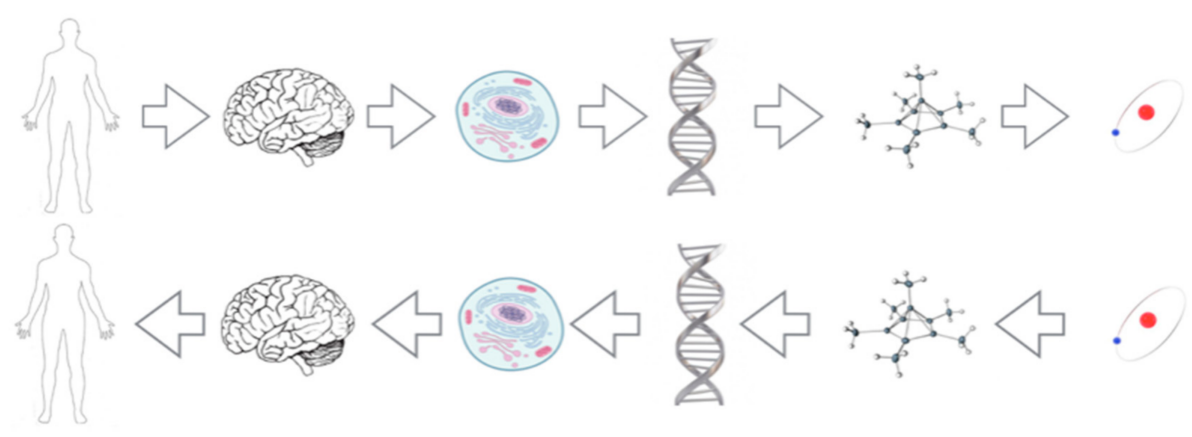

Figure 1. Reductionist versus holistic approaches. In the reductionist approach phenomena are separated and isolated into their component parts in order to understand the mechanisms unique to that level of reality. In contrast, in the holistic approach phenomena are connected and linked into networks or groups in order to understand the qualitative properties that emerge at higher level orders of reality. From the reductionist approach higher level phenomena are reducible to lower level phenomena, and from the holistic approach higher level phenomena can only be understood on the terms of their own emergent properties.

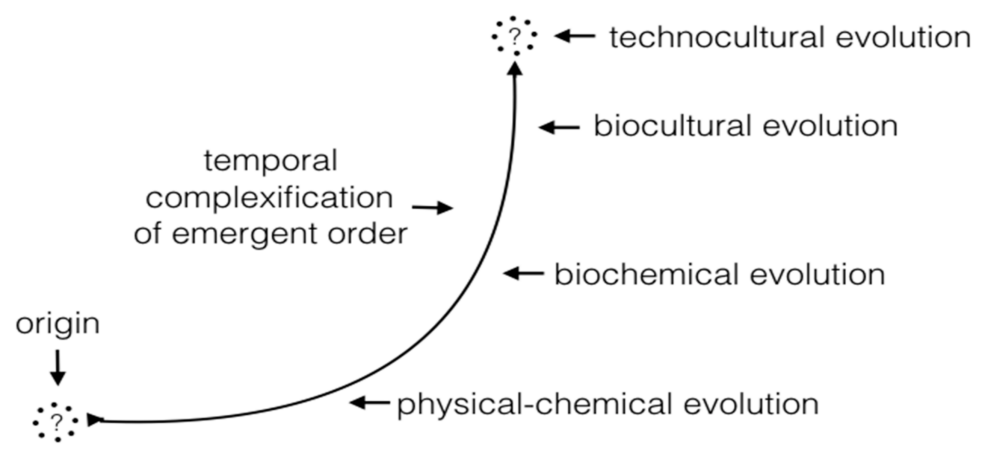

Figure 2. Big historical view of cosmic evolution. Throughout the history of universal evolution (change over time) phenomenon have undergone qualitative transitions enabling the production of new possibility and new order that operate under different basic rules or logics of change. In this schema two basic mysteries connect the beginning (alpha) and end (omega) of cosmic change with the origin of all known matter-energy and spacetime; and with the fate of the most complex known process which gives the signal of a potential future qualitative transition towards new possibility and new order.

These processes of change can be conceptualized in terms of a chain of rising complexity that generates qualitatively novel regimes of emergent order [58]. This is perhaps a more productive way to understand totality as opposed to classical conceptualization between different epistemological fields of study; or even between different ontologies of nature-culture, materialism-idealism. These regimes of emergent order can in turn be studied structurally from the simple origin of fundamental sub-atomic particles mediated by the forces of nature to the modern world of complex cognitive and social interactions mediated by the forces of ideation [59]. The logical next step would be to understand the nature of the rise of complexity and its ontological ordering consequences in relation to contemporary civilizational dynamics.

In order to approach this problem we must first clearly define what we mean by the term complexity. Complexity refers to phenomena that are fundamentally interconnected, enmeshed, and/or entangled in organizational networks of cause and effect [60]. The level of complex phenomena can be measured systematically by identifying the nature of the distinctions (meaningful differences) and connections (linked nodes) that define the organization from the lowest levels of physical order (strings, quarks, neutrinos, etc.) to the highest levels of social ideational order (languages, cities, 
cultures, etc.) [61]. Here we can say that a distinction introduces a division into being, whereas a connection introduces a unity into being. Thus, the analytical use of complexity in the cosmic evolutionary worldview allows for the situation of a clear and unified narrative frame of relational phenomena on all scales or levels from the sub-atomic [62] to the social [63].

Consequently, general theorists can use this frame to identify an increase or decrease in complexity when there is a change in the nature of the differentiated distinctions (divisions) and integrated connections (unities) that produce and characterize the qualities and intensities of the systemic organization [64]. For example, astronomers may identify that the universe began a complexification process when galaxies emerged because we can observe phenomena capable of higher connection (stars) through higher differentiation (chemical elements) than possible in the primordial universe. This process in turn birthed new qualities of spacetime curvature, heat radiation, photon emission; and also new intensities of nuclear fusion producing heavier substances [65]. The power of cosmic evolution to produce emergent qualities and intensities through connections (unities) and distinctions (divisions) is perhaps its most paradigmatic aspect [66].

The general trend in this complexity increase reveals a distinct arrow of time (from past to future via the present). This arrow is revealed because the mechanisms utilized by emergent phenomena to order itself are irreversible (future directed, from past to present) [67]. We may say that the temporal asymmetry of emergent phenomena is one of if not the most important distinctions between cosmic evolutionary philosophy and reductionist physical philosophy which presupposes the existence of temporally reversible eternal laws [68]. Consequently, the arrow of time can be described as an irreversible work driven by energy flows of particular dense and ordered configurations of material phenomena. These complex ordering phenomena are capable of overcoming the probabilistic statistical tendency of the universe towards greater levels of disorder or randomness [69].

In other words, because there are more ways for phenomena to be disordered than ordered (probabilistically), in the absence of local work energy directed towards more ordered states, phenomena will tend towards maximal disorder [70]. Thus when we look out at the history of an interconnected hierarchical universe and see galaxies, life, and mind in ordered configurations (instead of random organizations), we are looking at emergent patterns that evolved due to inherent internal tendencies to maintain order against a background that tends to void (Figure 3). This is true whether order manifests itself via the attractive force of physical gravitation which builds the reality of solar systems, the attractive force of biological fitness which builds the reality of ecosystems, or the attractive force of ideational desire which builds the reality of historical symbolic-systems. When contemplating the reality of physical solar systems, biological ecosystems, or historical symbolic systems we can thus think of all as part of the same cosmic evolutionary ordering force.

Thus the central remarkable aspect of the rise of complexity throughout cosmic evolution is that far-from-equilibrium organizational manifestations (i.e., changing order) tend to preserve themselves against the tendency to thermal-energetic equilibrium (i.e., maximal disorder) [71]. These organizational manifestations appear to achieve this feat through the evolution of increasingly sophisticated mechanisms of processing information which enable higher possibility spaces for actual development. In this sense we could conceptualize the arrow of time as concentrating itself multi-locally throughout the universe as a totality towards the virtual future with the potential aim of 'maximal connection' (highest unity) via the 'clearest distinction' (deepest division) given the virtual state space of the actual [72]. In our current philosophical notions of totality we have no idea how to consequentially integrate this reality into our conceptions of fundamental theory although it directly impinges on the futures reality of global technological singularity.

In our analysis we may say that the most fundamental aspects of these complex ordering phenomenon is that their identity is incomplete and open as opposed to complete and closed. Thus complex ordering phenomenon are themselves nothing but radical processes of becoming different (distinctions, divisions) in relation to basins of attraction (connections, unity) that emerge virtually as a consequence of actual relations [73] (Figure 4). This means that complex ordering 
phenomenon possess latent virtual potentiality which is invisible when observing the phenomenon at any particular moment, but which is still a part of the actual in the sense that actual phenomenon will tend towards virtual attractors that characterize its state space. In relation to the idea of a unified cosmic evolutionary ordering force this can occur in the physical order when a nebula becomes a star, or in the biological order when a seed becomes a tree, or in the symbolic order when a self-consciousness becomes a philosopher, or on the historical level when symbolic tribes become a global civilization. In all situations we do not have complete and closed identities reversibly existing from eternity but incomplete and open identities irreversibly existing in an asymmetrical temporality. In other words we have identities that are nothing but a process of becoming.

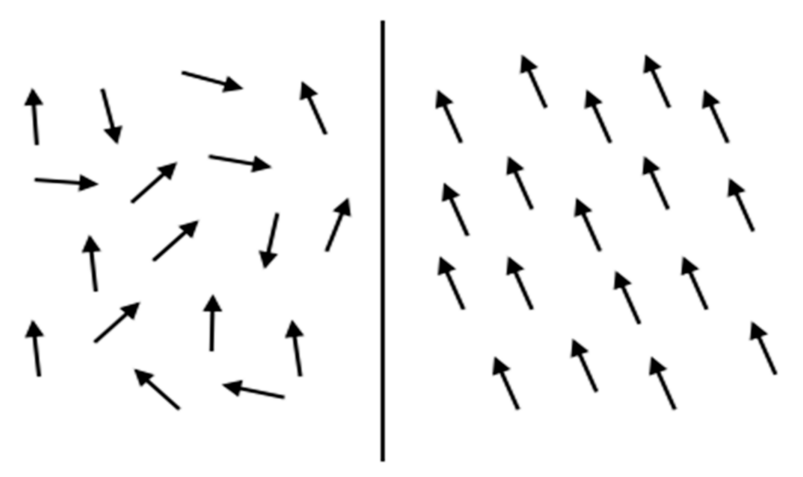

Figure 3. Disorder and order of phenomenal telos. For a disordered phenomenon (left) there is no discernible regularity of motion to be found in the constituent elements of the system as a whole. Consequently, disordered phenomena do not produce far-from-equilibrium emergent order. For an ordered phenomena (right) there is a discernible regularity of motion (a type of 'pattern') that operates on particular rules or logics which enable the phenomenon to dynamically maintain itself over the course of time (e.g., biological information of DNA, linguistic information of language are good examples of ordered phenomenon that maintain themselves with particular rules or logics). Consequently, ordered phenomenon are capable of producing emergent phenomena that are in turn capable of maintaining themselves further and further from disorder (i.e., 'higher orders' like biology from chemistry, or like symbolic from the biological).

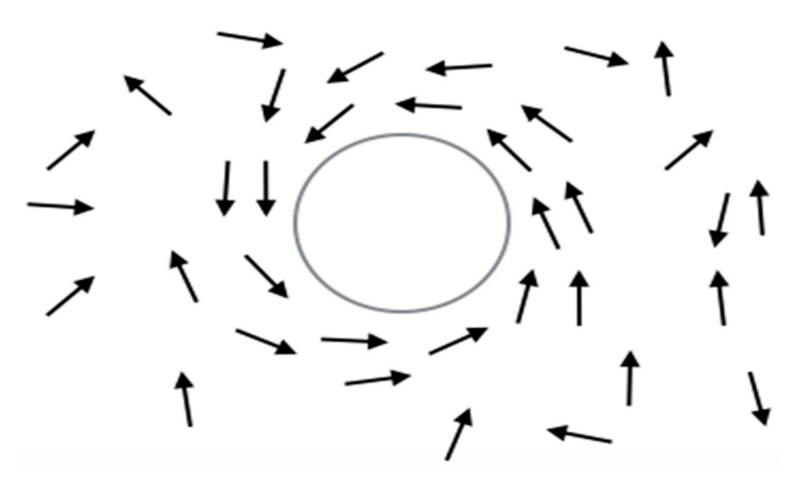

Figure 4. Becoming in relation to basins of attraction. Ordered phenomenon tend to have a collective direction of motion in relation to basins of attraction where all or most constituent parts orient informational function towards a goal-object that could not be achieved by any one part independently. For example, on the level of physical order a solar system only forms when planetary bodies orient motion around a collective center of gravity; on the level of biological order a cell can only form when chemical components orient motion around a collective central chemical code; on the level of symbolic order a society can only form when conscious components orient motion around collective central linguistic code. 
In the human symbolic realm this potential aim appears existentially on the ideational horizon in the form of universal ideality (i.e., dreams, fictions) [74]. These dreams or fictions can either represent attractive or repulsive virtuality that exist phenomenologically but do not exist in the actual as observable. In other words the reality of this virtuality is only as a potentiality of consciousness in the sense of a state space with capacities that depend on the finite actual for embodied and embedded motion. For example, for both human individuals and collectives a dream or fiction structures the becoming of process, which can either relate to the individuation of a self-consciousness or the collectivization of a symbolic system. Thus, dreams and fictions in the human world are not merely epiphenomenal but fundamental to the emergent development of our realm. In their most extreme and powerful metaphysical expressions dreams and fictions may be described as future-oriented desires driving repetitive distinctions (divisions) attempting to form higher connections (unities). On the terms of individual self-consciousness this may be conceived of as something like the 'overman' (higher self); and on the terms of collective social systems this may be conceived of as something like 'utopia' in secular context (higher civilization), and 'heaven' in transcendental context (higher being). In all cases we are dealing with the nature of the highest or deepest values, purposes, and meanings as emergent basins of attraction which structure phenomenal historical becoming.

This cosmic evolutionary philosophy as foundational worldview could challenge our dominant cosmological conceptions grounded in thermodynamics of an imminent tendency to universal disorder (Figure 5). In this philosophy the immanence of higher orders may be currently absent, existing only as an invisible potentiality internal to and dependent on the actual intensities and qualities of a future qualitative phase transition (Figure 6). Furthermore, these actual intensities and qualities of a future qualitative phase transition could be driven by psychosocial processes that are equally fundamental to lower order reductionist physical models of reality that cannot approach the irreversible temporality of complex ordering phenomenon. Or it could be that reductionist physical models are necessary conceptual structures for the actualization of the next qualitative phase transition. The clear location of this new complex order should be concretely related to basins of attraction of the differentiated distinctions related to human beings (divisions) and the way in which their psychosocial intensities and qualities are coordinated and constrained in integrated connections (unities). In the global technological singularity literature the future divisions are often represented as artificial general intelligences and the future unity is often represented in terms of distributed digital networks $[75,76]$. 


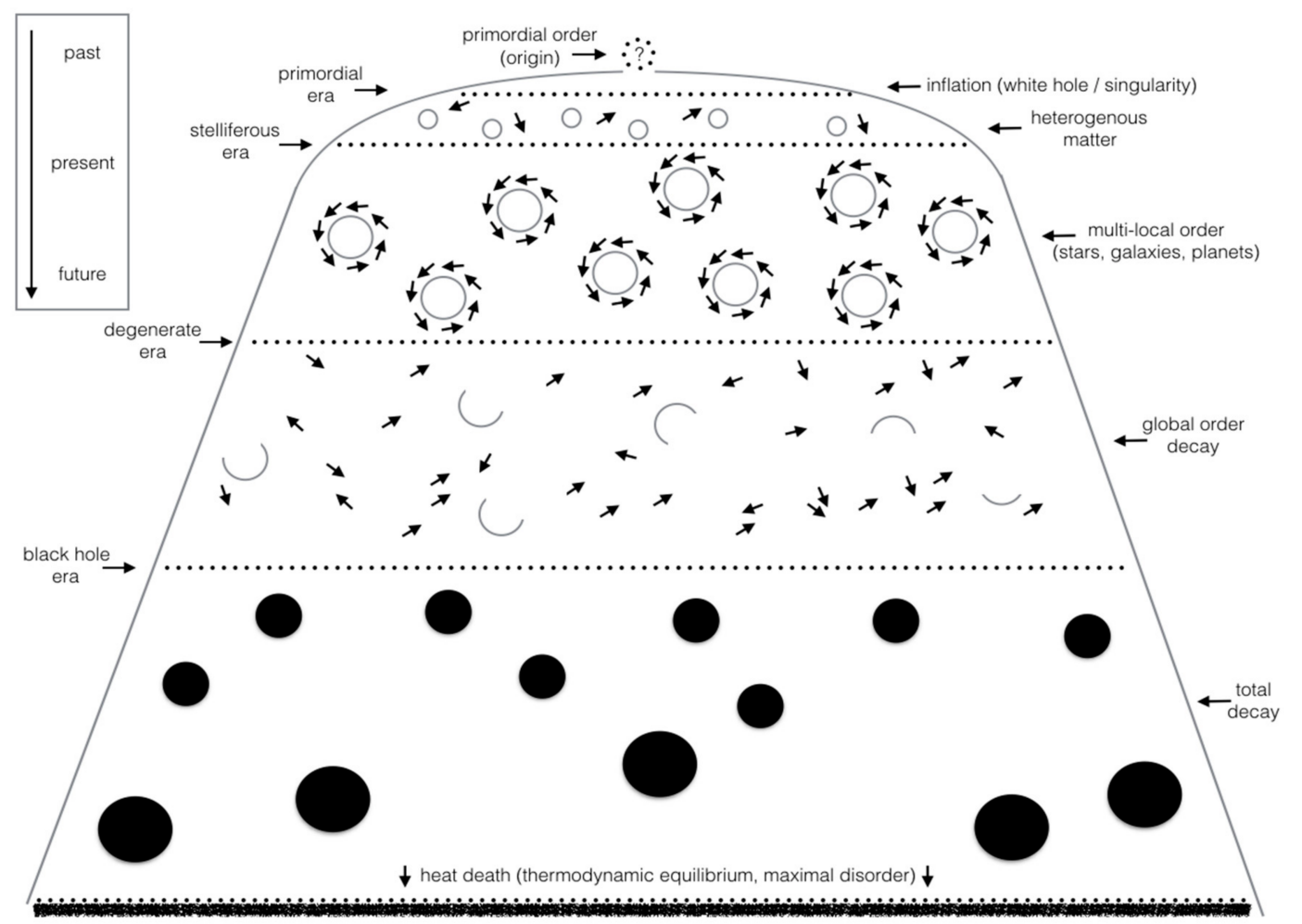

Figure 5. Thermodynamics view of the cosmos, primordial order to final disorder. The thermodynamics view of the cosmos gives the picture of a universe with particular low-entropy, highly ordered or supersymmetrical initial state of being (non-random motion). This initial state drifts towards higher-entropy, global disorder (random motion) over time via symmetry breaking events (divisions) and feedback loops (unities) which generates a motion that we understand as an arrow of time. Consequently, in the context of the universe as a whole (considering the whole of space and the whole of time) the most common state space for matter is general disorganization (thermal equilibrium) due to low material interaction rates, which suggests that the currently observed state of the universe is ultimately unstable. The multi-local material order that does self-organize into persistent temporal form (galaxies, stars, life, mind) occurs due to gravitational attraction acting on heterogeneous distributions of organization which enables higher material interaction rates. In our current understanding of the universe there is no complete theory that explains the fundamental consequence of the emergence of such multi-local order, and reductionist perspectives tend to regard such phenomena as epiphenomenal. In other words, reductionist perspectives identify a fundamental objectivity (unity) framed a priori by a subjectivity (division), but cannot think a framed a priori subjectivity (division) that constitutes an emergent fundamental objectivity (unity).

From the level of phenomenology this places importance on experiential horizons of reality that are more fundamental to being than any particular forms of scientific knowledge (i.e., thermodynamic theory) [77] (Husserl 1970). These horizons function as new levels of appearance for interaction and as new platforms for potential complexification to be ordered by the future-oriented cognitive agents under the particular attractors and constraints unique to that level of becoming [78]. Thus the cosmic evolutionary worldview suggests that our universe possesses a denser concentration of relation and a more lively cognitive destiny filled with more adventure and mystery than is often conceived in dominant conceptual paradigms [79]. In this way the thermodynamic worldview positing an inevitable tendency to maximal disorder or non-being [80], may be missing a crucial part of the picture: the nature and future immanent potentiality of ideality inherent to the symbolic order of being $[77,81]$. If we include this potentiality we must also consider the possibility that there exists a to-be-actualized singularity of ideational order that cannot be thought in the thermodynamic conception of the cosmos. 


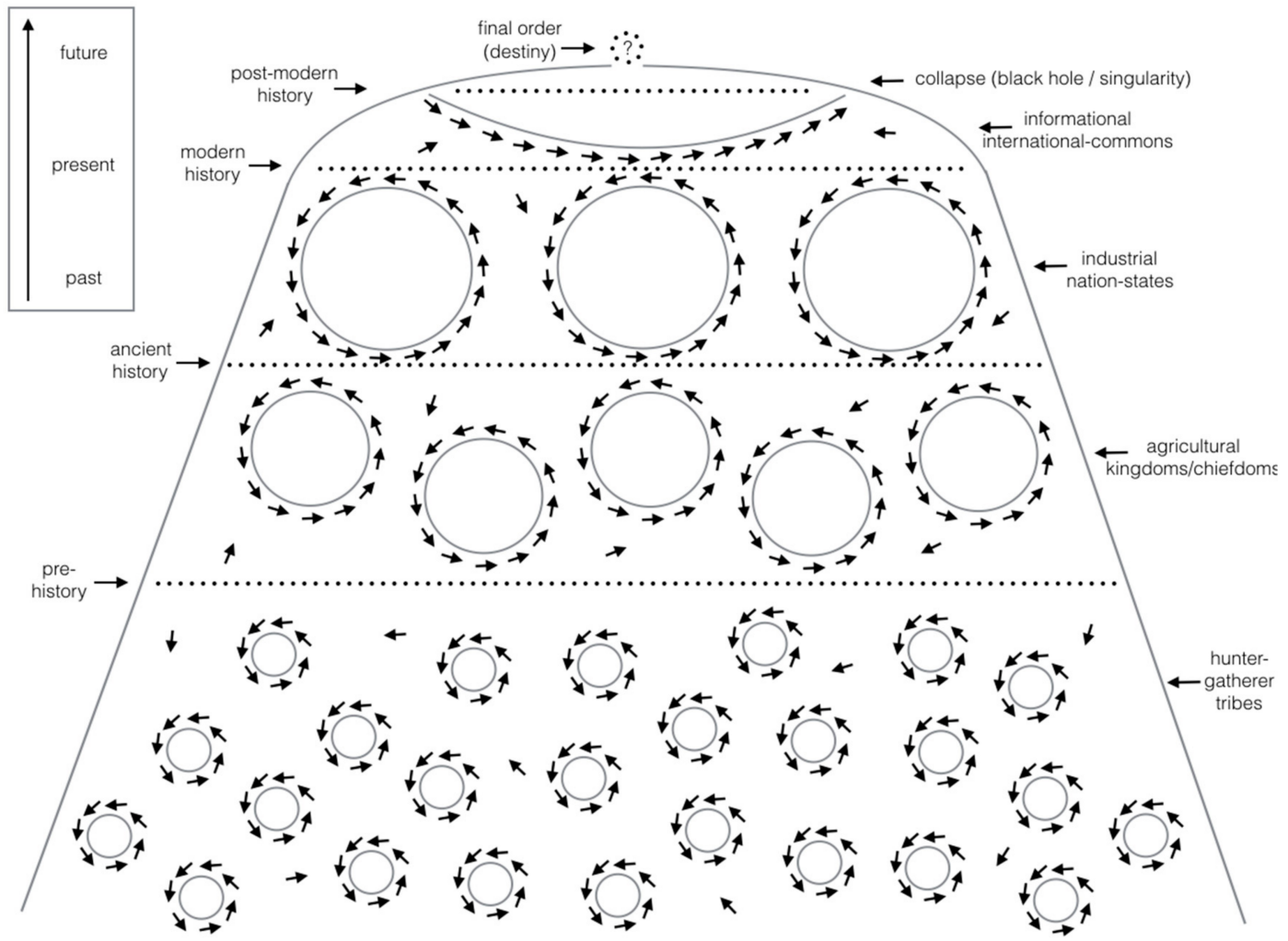

Figure 6. Teleodynamic view of the (local) cosmos, primordial disorder to final order. The above representation attempts to capture the cosmic evolutionary worldview that is characterized by far-from-equilibrium or non-equilibrium systems that operate on self-organizing principles dynamically balanced between chaos and order. In the teleodynamic conception we get an image of the world that presents us with an immanent 'immortal heat' where highly ordered far-from equilibrium systems curve their being to a state of supersymmetrical unity (a cosmic-transcendental monism). Such a state would likely annihilate the dualistic distinctions between subject-object, concept-world, observer-observed, material-ideal without resorting to a pre-linguistic 'biophysical grounding' that ignores the emergence and consequences of conceptual distinctions (i.e., 'distinction-division dynamics'). In this representation the totality of process is conceived of as starting with the emergence of a field composed of ideationally constituted social unites (bands/tribes) whose ground is self-consciousness developing in language. Throughout the historical process bands/tribes become progressively 'synthesized' into higher level social unities which has the effect of reducing the number of different unified groups (i.e., fewer unities) but increasing the spatial scale of the unified groups (i.e., the difference between Europe pre-and-post Roman Empire, or the Asia pre-and-post Chinese Empire, etc.). In this progressive trend to unification the level of individuation also progressively increases meaning that there are emergent degrees of freedom for the particular elements of the higher level social unities. This paradox between higher social unity and higher individuation continues to the present day where we see the dominance of a 'multiplicity of ideals' which are nonetheless all expressing ideality within one universal technological medium. The combination of these two trends make it difficult for philosophy to make sense of totality. In this view in order to approach totality we must include the radical divisions characteristic of individuation into the higher unity of totality, thus creating a unity inclusive of division.

\section{Dialectical Approach to Technological Singularity}

In order to continue this analysis we here shift focus from the object-oriented cosmic evolutionary philosophy itself towards understanding how we can utilize this philosophy dialectically as it relates to an internal subjective approach to global technological singularity. The objectivity of human motion mediated by universal ideation is not fully understood in either the classical mechanistic 
worldview (scientific materialism) or the classical transcendental worldview (philosophical idealism). This is because scientific materialism reduces everything to physical motion governed by eternal laws, and philosophical idealism integrates everything into the eternal concept which transcends physical reality. Thus both approaches fail to capture the dynamical intersubjective becoming of ideality and its historical effects and consequences in relation to totality. In order to approach ideational motion embodied and embedded intersubjectively in a material world we must understand the real consequences of an emergent subject-object division (or observer-observed, mind-matter, concept-world) as itself a dynamical part of totality (i.e., freedom is part of totality).

When we start with a totality constituted by subject-object division (as opposed to starting with a subject-less objectivity, i.e., big bang; sub-atomic realm, etc.) we are starting with the asymmetrical becoming of our own phenomenal existence which appears to freely aim for a higher unity (or 'oneness') on the individual level of self-consciousness and on the collective level of social systems ('self-actualization'). The subject-object relation is of fundamental importance when reflecting on a global technological singularity as an objective real event. This is because we must understand how objectivity itself depends on the activity of open and incomplete observers manifest as intersubjective networks striving for self-actualized unity within multiplicity. To approach this phenomenon we will rely on a philosophy of materially grounded idealist dialectics, and we will rely on the science of psychological self-analysis whose focus is the objective content of ideal becoming. In other words, what we get from a synthesis of scientific materialism and philosophical idealism is a dynamical intersubjective objectivity with a locus of causality internal to conscious ideality as fundamental reality [82].

The mediation of an ideal intersubjective objectivity gives us a potential human-centric perspective on approaching technological singularity theory where human observers are the active psychosocial drivers of process. To be specific this dialectic operates on general negations of the world as given (divisions) coupled with affirmations of an alternative idealized world (unities). In the present the conceptual motion of negation and affirmation occur within the unified medium of the internet which enables both a higher level of individuation (division) and a more totalizing universality (unity) than ever before in human history [57,78]. Here ideal negations and affirmations are phenomenologically tested in relation to the actuality of their enacted transformative consequences. In other words, a particular individuated division repetitively attempts to introduce and maintain the actuality of a simple unity in being against a complex background. In this general motion of ideality transformations retroactively change the subject-object relation, and thus totality itself, by creating and mobilizing psychosocial processes towards new ideal realities [83]. In order to approach this divided field, a general motion can potentially be formulated under a schema of triadic logic [44,84] from (1) theoretical abstractions (imaginary) to (2) enacted transformations (symbolic) to (3) concrete actualization (real) (Figures 7-10). 


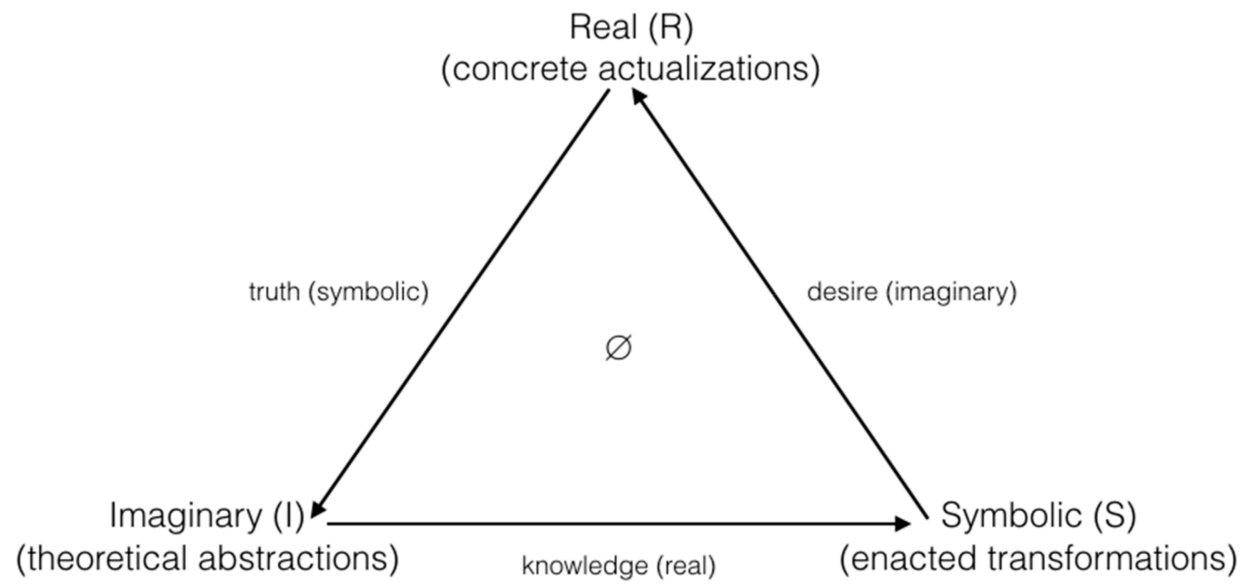

Figure 7. Structural transformations on the transcendental horizon: triad. This structure represents an attempt to formalize the geometry of the mental space which becomes entangled with the world. From this entanglement we see the motion of the dynamical geometry of the mental space as concretizing new reals from knowledge by processing imaginary desire through symbolic truth acts. First, the subject that intervenes/transforms emerges from the concrete real in relation to an imaginary field or screen. This field or screen becomes the invisible location of the subject's thought on its perceptual horizon of becoming and reveals to the subject an object of desire which motivates it to intervene/transform the real towards a more ideal order. The subject achieves such interventions/transformations through introducing the symbolic to the real in the form of speech, writing, poetry, song, equations, jokes, and various other formalisms. From introducing the symbolic into the real the subject becomes fundamentally entangled, correlated, and/or caught up in a web of interactions with the real and thus measures its symbolic on the terms of which the real returns its message as truth (intervention/transformation). In these processes all three elements of the imaginary-symbolic-real are simultaneously co-present: the real of knowledge is present when the imaginary theoretical abstractions collapse into enacted symbolic transformations; the imaginary of desire is present when enacted symbolic transformations attempt a real concrete actualization; and the symbolic truth is there when the real of concrete actualizations informs theoretical abstractions of the imaginary. In this scheme 'knowledge' is 'real' because knowledge is the concrete actualization of the subject, 'desire' is 'imaginary' because desire represents an absent actualization, and 'truth' is 'symbolic' because truth is what returns to the subject from the real (an 'answer' from the real that 'emerges' due to our own interventions/transformations). In order to interpret and utilize this structural triad it is crucial that one conceives of it as always-already ('eternally') in motion and constantly re-setting its coordinates in a network of such structures which compose the geometric space of the four-dimensional transcendental horizon. The central $\varnothing$ denotes that 'beyond' or 'behind' the transcendental horizon there is nothing other than the void of our subjectivity which we project (imaginary) and enact (symbolic) into the real. In this way such an analysis attempts to think a dynamical real virtual thing-in-itself (between order-chaos, dreams-obstacles, goals-challenges, presences-absences etc.) that is both open and incomplete making the 'thing' dependent on subjectivity for its own identity and becoming due to a division that is fundamental for the appearance of subjectivity as such. 


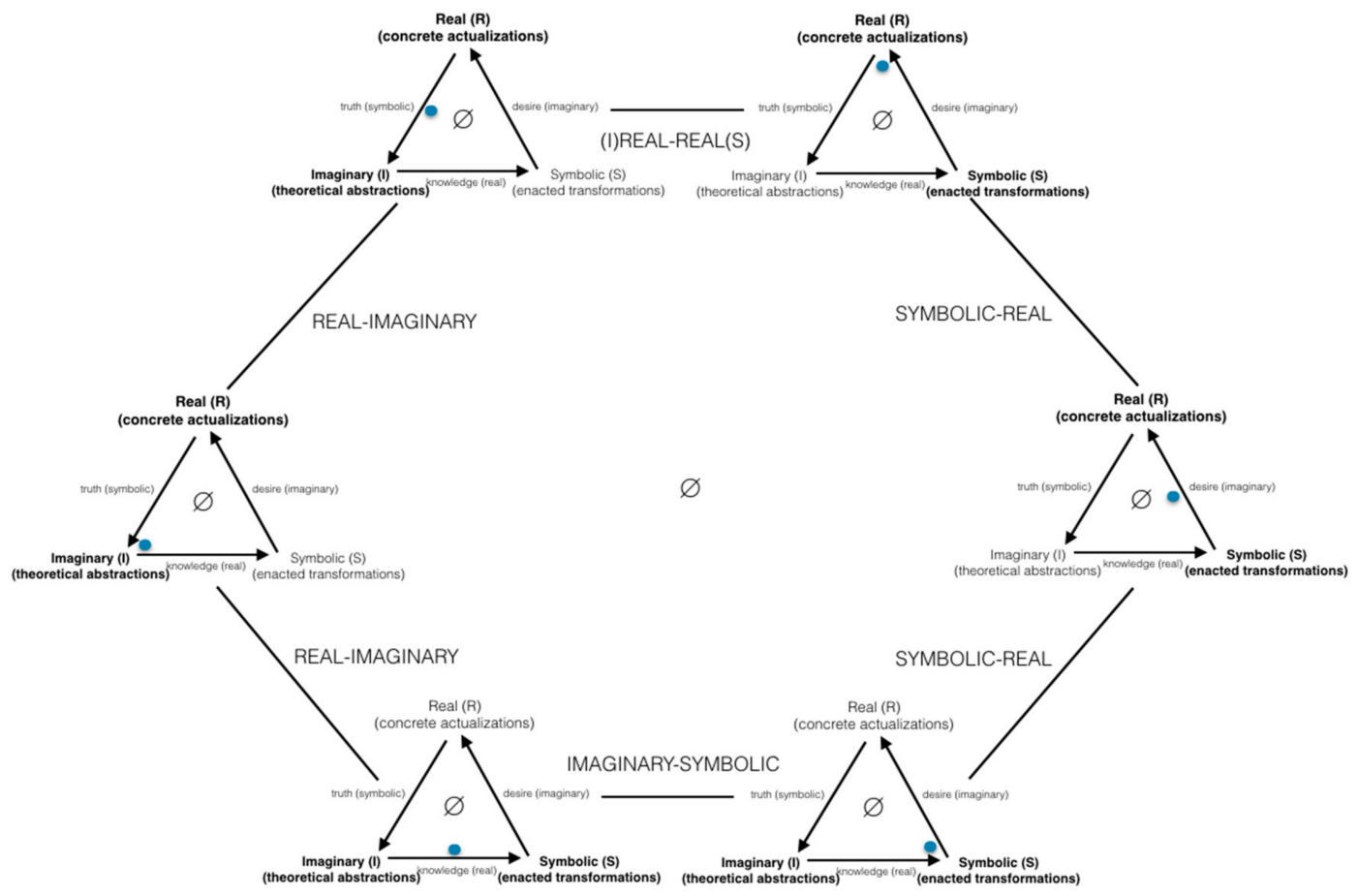

Figure 8. Structural transformations on the transcendental horizon: cyclohedron. The geometry of the triad is a classical structure of logic used to study the nature of the human mind (e.g., for psychoanalysis: [85]; and philosophy: [86]; see also: [87]). However, in order to capture a larger view of totality in triadic transformation we must also represent the dynamical motion with a higher dimensional cyclohedron representing the circular-orbital temporality of desire (blue dot, objet a) as it passes from imaginary-symbolic, symbolic-real, and real-imaginary. Cyclohedrons complexify triads in geometrical analyses used to study knot invariants $([88,89])$. Here knot invariants are desire deadlocks (points of impossibility) fundamental to understanding the structure of pure desire. In this frame 'knots' can be located on the level of the symbolic transformation which generates a perceived subjective separation/connection (in space) and distance/closeness (in time) from the 'real event' as the 'desired state' (ideal-real). In other words, when symbolic transformations 'miss' on returning from the real there is a subjective emptiness (filled only with the real of imaginary potentiality), and when symbolic transformations 'hit' on return from the real there is a subjective fullness (where the imaginary intersects with the real actuality of desire).

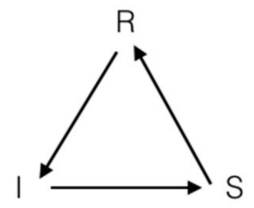

Self-Arrow (Structure)

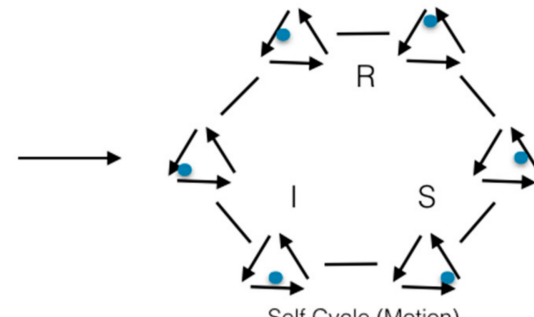

Self Cycle (Motion)

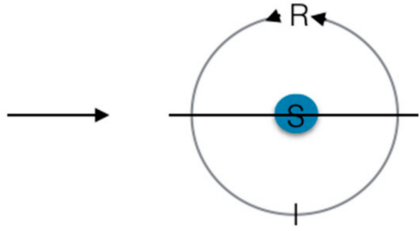

Self Drive (Unity)

Figure 9. Structural transformations on the transcendental horizon: not-One. In the higher orders of Self we find a Unity in the not-One where the Real of openness and incompletion is fundamental to the Self's internal Unity. The inner discovery of this Unity shifts the subject from a mode of pure desire to pure drive. In the mode of pure drive the gap/difference the Imaginary detects in the Real produces a Symbolic rotary motion of pure enjoyment (ideal-real) where desire is 'eternal'. 


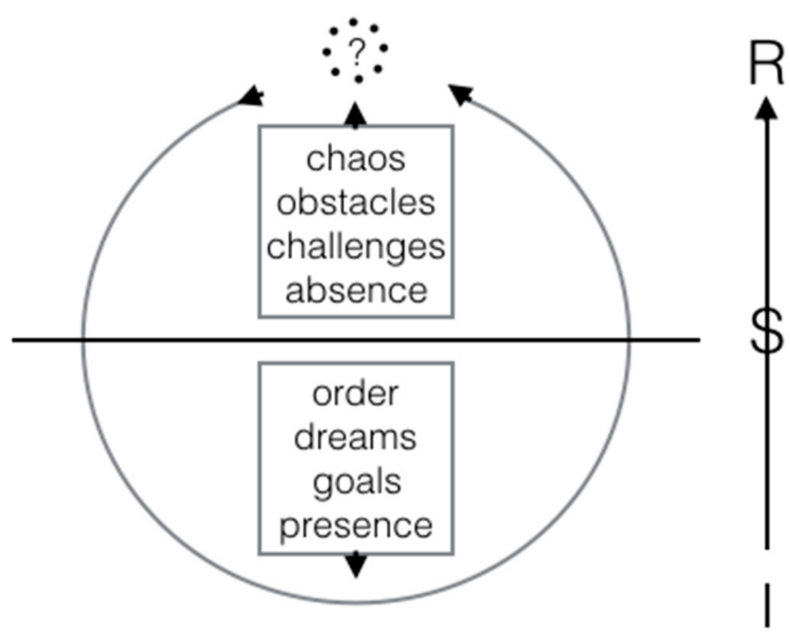

Figure 10. Totality as not-One, dynamical structure of the transcendental horizon. The totality or 'thing-in-itself' is not only 'real virtuality' but in-itself a dynamical becoming (making it 'not-One'). This not-One is thus irreducibly dual (subject-object, concept-world, human-nature, mind-matter, etc.) and split between ontology/being that resists and epistemology/knowledge that insists. On the ontological side of the 'impossible thing' which resists our grasp we may place the domain of chaos, obstacles, challenges, and absences; and on the side of the 'transforming consciousness' we can place the insistent grasping domain of order, dreams, goals, and presences. The subject caught up in the triad of the imaginary-symbolic-real of this process (self arrow) is what dynamically traverses both sides of the dividing line between order-chaos, dreams-obstacles, goals-challenges, presence-absence in an asymmetrical future-directed motion. In other words the subject is what invades being with epistemological insistences ('projects'), and experiences in return ontological resistances. The subject attempts to bring order to chaos, achieve dreams that overcome obstacles, reach goals that nihilate challenges, and to make present which was once absent through its symbolic transformations. In analysis of this open and incomplete 'thing-in-itself' can we possibly think the actualization of the thing-in-itself as One or is totality nothing but reducible to this impossibility as not-One? What is in the end the status of this gap/difference internal to the thing-in-itself?

Thus, in focusing on an ideational motion structured by triadic logic operating internal to a field of multiple observers totality itself becomes open, incomplete and dependent on intersubjective ideality for its actuality. Thus in this frame totality itself is nothing but the ideational space of observers where epistemological knowledge practices become entangled with fundamental ontology. Here knowledgeable observers become effective agents that are directly involved in transforming the physical world via conceptual mediation. From such a program we are invited to engage with a spatially curved epistemology due to the inclusion of desiring subjects that develop strategies for coping with internal symbolic deadlocks produced as a consequence of division from unity (or 'points of impossibility'). We are also invited to engage with a temporal dynamic ontology due to the inclusion of the ontic effects of subjects own projected interventions and retroactive reflections aiming for unity. This intersubjective motion is structured by a multiplicity of ideational networks capable of negating-affirming (transforming) the distance between the actuality of friction (zero-sum) and the ideality of synergy (positive-sum).

In this frame totality becomes a radically asymmetrical temporality of ones dualistically imbalanced between being and absence [90], order and chaos [91], dream and obstacle [92], goal and challenge [93]. Thus, in terms of subject-object (observer-observed, mind-mater, concept-world) division we have clear separation and distance from any understanding of totality as eternal unity (physical/material or conceptual/ideational). On the side of the subject, we find our being immersed in nature, we find an order that frames the world, we find a dream that orients action, we find a goal to transform the given. On the side of the object we find an absence in being, we confront an 
unknown chaos, we find that there are obstacles on our path, we find that movement is a challenge. Such separation and distance represents an eternal division that disturbs the possibility of eternal unity but allows for the asymmetric temporality of free representations in historical becoming. Here totality is not closed and complete but in need of a reconciliation which involves the active participation of every observer as a background independent field of ones (individuals). Such reconciliation can be framed experientially as a desire to enter a flow state or drive that would actualize a qualitative phase transition towards a higher order state of unified being.

When thinking totality as an eternal division to be reconciled in these terms we may posit that a future actual singularity is immanent in the potentiality of our action even though we have no idea what will manifest on this pathway. Here consider the general epistemological structure of scientific networks as forces that aim to transform being and retroactively change the way in which we think about subject-object division as totality. The most obvious historical examples of this retroactive change include the industrial technology revolution which changed our conceptions of the energetic cosmos (i.e., thermodynamics, etc.), and also the computer technology revolution which changed our conceptions of the informational cosmos (i.e., cybernetics, etc.). These examples are so general that when we are thinking about the desiring subjects who drive the future of robotics, nanotechnology, genetics, quantum computing, and so forth, it is hard not to conclude that the logical immanence of their own sets of ideal conceptualization schemes will retroactively change our fundamental conceptualization of reality on the level of universal history [94]. Indeed, it could be that fundamental reality or totality depends on the intervention of conceptual observers and their technic apparatuses in order to be constituted and thus realized.

Of course in this process not all modes of individuation are equal because not all individuations lead to effects of universal historical significance. Consider an extreme example of individuation with consequences for universal history with the most (in)famous technological singularity theorist, Ray Kurzweil, and his sets of ideal claims about future immortality $[20,21,95,96]$ (which emerge against the background of a fear of death (i.e., separation and distance from eternal unity)). In a dialectical analysis of the higher order ideational space the point would be to understand the effects and consequences of this ideality in terms of their abstract powers to transform being for all other individuated observers. These abstract powers include the force of a paradigm that can directly or indirectly create and mobilize psychosocial environments of potentially extreme relevance to universal history. For example, in the case of Kurzweil's set of conjectures we have psychosocial systems as unities focused on creating the next generation of artificial intelligence. These psychosocial environments have gained a symbolic autonomy in chains of communicative events which are unlikely to be prevented from exhausting their potentiality. The nature of subject-object division will be forever transformed as a consequence but what dynamical state of phenomenal being will they actualize?

Consequently, all processes of individuation are crucial for the reconciliation of universal history on the highest orders. This is for the simple fact that all subjects are an effect of the eternal division and all subjects are ultimately responsible for producing an internal unity capable of withstanding this asymmetrical imbalance. In thinking about the technological singularity with such dialectical tools we aim to reframe the position of humanity in the philosophy of science and the sciences of humanity as a whole. This ultimately requires us to understand the motion of general ideation as it will be effected by scientific ideational reduction and fragmentation as they are currently manifesting and evolving spatially in curved virtual fields [97]. These virtual fields include ideational forms as diverse as M-theory in particle physics, artificial intelligence in cognitive science, and genetic engineering in biology. All such fields could be technically modelled from the point of view of a temporally asymmetrical totality in a state of subject-object division. The collective nature of this state space suggests that the actuality of human civilization must include within it an invisible potential tendency to transcendence of present being that can be discursively mediated in relation to a central desire for higher order unity. 
In order to demonstrate the functional or pragmatic utility of such a seemingly complex notion of totality let us now consider an example of how this approach can help us understand the higher orders of scientific ideation operating under paradigms of fragmented reduction. The example I will choose in this analysis of totality is the example of the theoretical particle physics community. The reason to consider this community as a particular example with general relevance to global technological singularity theory is that this community is the best example of fragmented ideational reduction applied towards a unified theory of totality. In contemporary particle physics theory ideal abstractions conjecture a theory of quantum gravity capable of understanding physical singularities (black holes, big bang). In order to realize this the theoretical particle physics community holds a particular set of ideality about the nature of the world (i.e., standard model, M-theory). These abstractions aim to understand the hypothetical dimensions that may represent the fundamental constituents of physical matter at the smallest scale of reality.

Now when we are thinking about the particle physics community as a psychosocial force produced as an effect of subject-object division aiming for unity we have to think about how this asymmetrical imbalance generates ideational conflict and tension. This conflict and tension can be situated around the aforementioned dualistic eternal couples of totality: being-absence, order-chaos, dream-obstacle, goal-challenge. Here we see that the particle physics community emerges as an epistemological desire that will retroactively change ontology (i.e., standard model is incomplete logic, M-theory is open speculative conjecture, etc.). Thus, in the higher order theory where we include the observational multiplicity as fundamental we could posit that abstractions in the form of the standard model and M-theory enter into a negative relation with given being. This occurs in so far as the projected ideality of M-theory posits a future reconciled or completed state (imaginary) within which totality will be transformed towards a comprehensive notion of the fundamental constituents of physical matter (symbolic) which would allow us to understand the origins and fate of all matter (real).

However, on the first order of analysis there has been little progress in understanding quantum gravity in terms of concrete predictions. This is due to the inability to test the real of projected ideality that would help us understand the origins and fate of all matter. The result of such obstacles leads to fundamental theories disconnected from the classical reality of scientific materialism and much more connected to the classical reality of transcendental idealism. Thus, in order to avoid both eternal structures it could be that a higher order perspective emphasizing the eternity of a subject-object division attracted towards an emergent unity constituted by intersubjectivity could be what is missing from our consideration of fundamental problems related to quantum gravity. In the higher order frame the solution to quantum gravity must contend with the real becoming of observers constituting the transcendental horizon. In other words a higher order theory of quantum gravity would not only have to explain the nature of the big bang and black hole singularities, but also the nature of conscious observers in the potential actuality of a technological singularity (Figure 11).

In this context the particular example of analyzing the particle physics community and their first order search for unified totality becomes extracted to the higher order and applied to general psychosocial systems. This seemingly strange move in relation to understanding unified totality has fundamental implications for reductionist theories that attempt to explain everything. For example, a common feature of modern scientific discourse is the claim that a grand unified theory is within our grasp. However, when we consider this proposition in our present context, is it even possible for us to imagine what a grand unified theory would actually mean for the subject-object division as totality? What would it mean if communities of physicists developed a grand unified theory of quantum gravity as a reductionist master theory of the universe? In other words, would such a theoretical development (imaginary) have any practical transformative consequences (symbolic) for the emergentist subject-object division as totality (real)? Would it mean that something fundamental would change for the nature of temporally asymmetrical and irreducibly perspectival discursive reality? 


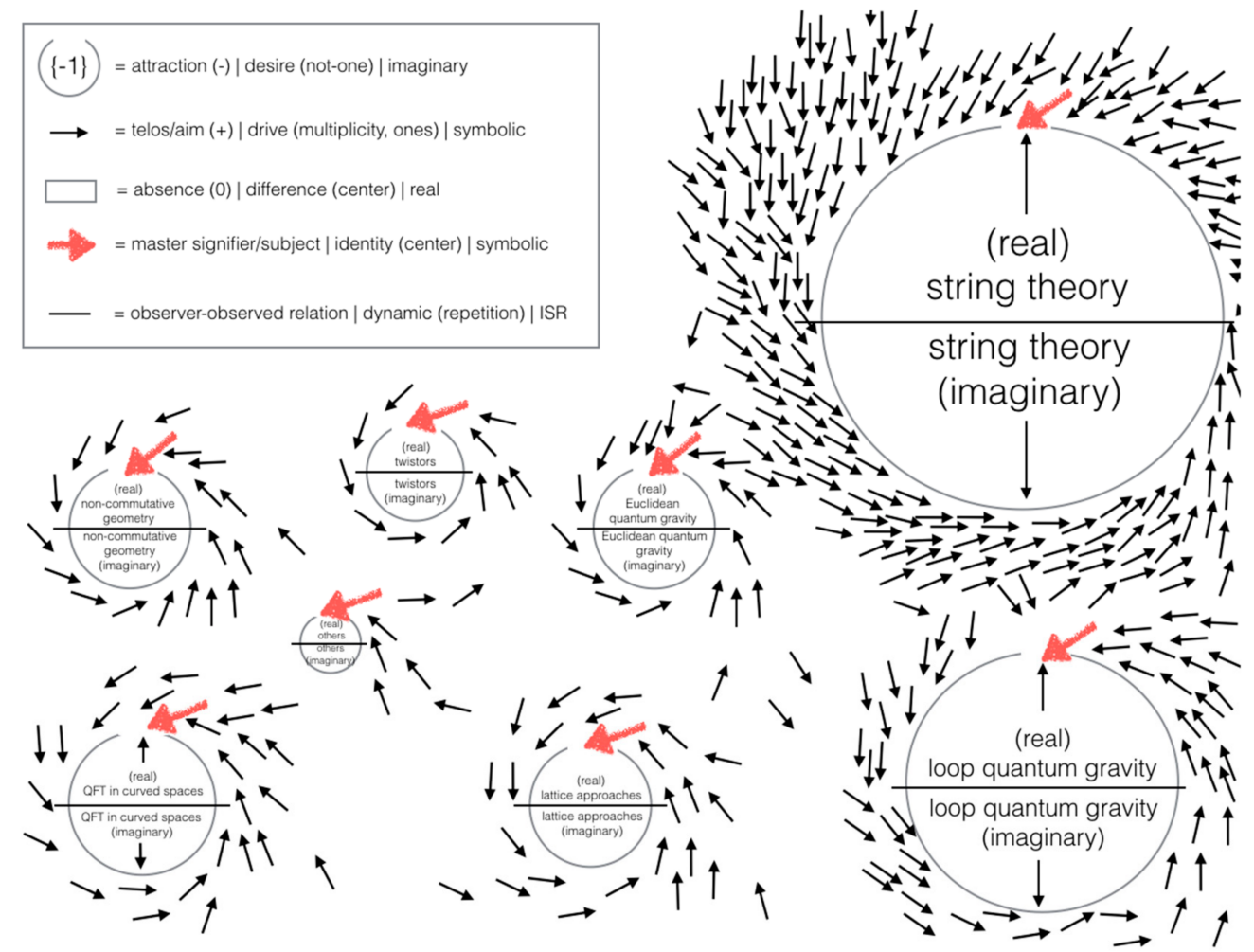

Figure 11. Psychosocial virtual field of physics communities. The above figure attempts to capture the general psychosocial virtual field of quantum gravity in relationship to the main abstract theoretical groups (imaginary) which aim to transform the concept-world relation through enacted transformations (symbolic) by concretely actualizing the 'true' understanding of quantum gravity (real). The red arrows represent a 'master signifier' or 'main subject' which could be dominant concept(s) or person(s) in the respective fields (i.e., 'strings' and 'Ed Witten' or 'loops' and 'Lee Smolin') which orient the symbolic weight and aim (topography of black arrows) of the ideational field in relation to the absent real. The closer the network of arrows/signifiers to the real the closer they are to the in-itself of the social-historical meaning of the semiosphere. For example, black arrows (symbolic transformations) close to the site of the real may be fellow professors or graduate students with the trailing arrows representing lower levels of relation to the site of the real, i.e., colleagues, other scientists, educated public, undergraduate students, etc. In these relations the bar of the circles represents the dynamic border of the 'thing' (from order/dream/goal to chaos/obstacle/challenge and back) that can be symbolically conceptualized in light of the linguistic formalisms S I s denoting the signifier's freedom and autonomy over and above the signified [98]. This is best demonstrated by physics communities whose signifying chain tends towards the in-itself of internal-imaginary consistency before it is validated by the return from the real. These represented social systems can be divided down the 'three main roads' of quantum gravity, i.e., (1) approaches that start with quantum mechanics (e.g., string theory, QFT in curved spaces), (2) approaches that start with general relativity (e.g., loop quantum gravity, twistors), and (3) approaches that start from novel presuppositions that rethink the foundation of both quantum mechanics and general relativity (e.g., 'others') [99]. The specific sizes of the psychosocial gravitational fields in this representation correspond to data collected by Carlo Rovelli at the International Congress on General Relativity and Gravitation on the count of articles published in each respective field of quantum gravity [100]. Of course what this representation does not capture (requiring more sophisticated modelling) is the dynamic motion, the interaction, and the change over time of these communities. Such a model could potentially approach questions about why many different socially constituted physics tribes seem to be able to produce correct solutions to the origin and fate of matter with different fundamental constituents of quantum gravity [101] and thus also potentially help produce a higher order relational understanding of reductionist attempts at complete-closed grand unified theory modelling. 
In proper philosophical terms a grand unified theory can be conceived as an eternal unity often represented on the level of understanding as absolute knowledge [102]. However, this unity would logically nihilate the primacy of the subject-object division whose broken symmetry is causative of ideationally constituted intersubjective becoming. Consequently, whenever we are approached with first order notions of a grand unified theory we should never forget that these abstract conjectures central weakness is their inability to deal with the (still moving) higher order psychosocial forces where the subject-object division is left without total reconciliation. Thus, when it comes to theories of quantum gravity it may be necessary to situate those dealing with subject-object division as the synthetic 'third path' in contrast to the first path grounded in reconciling general relativity with quantum mechanics (e.g., string theory); or the second path grounded in reconciling quantum mechanics with general relativity (e.g., loop quantum gravity). In the third path what becomes crucial and indispensable is the asymmetrical nature of time and the meaning of a universe in which we are active participants [103].

\section{Consciousness and Universal History}

We have attempted to build a cosmic evolutionary philosophy and situate within this philosophy the fundamental dynamics of ideational motion on the horizon of universal process. Now we will attempt to situate ideational motion within a higher order theory of consciousness that can approach totality. In this theory of consciousness, we place less emphasis on the physical instantiation of consciousness within a materialist foundation and instead place more emphasis on historically-engaged phenomenal understanding as it relates to a fundamental truth of unified reality. In other words, this analysis is less concerned with whether consciousness is produced by neuronal activity, or by the quantum level of being, or by some other unknown physical mechanism; and is more concerned with the phenomenal activity of psychosocial forces as they relate to the historical search for the truth of reality.

In building this theory of consciousness, our analysis will forward a different perspective then most reflections since it will offer an emergentist mental theory, as opposed to a scientific reductionist theory or philosophical transcendentalist theory, seeking to understand totality in terms of its relevance to the meaning of human existence. This approach to totality is different than most contemporary theories because, instead of explaining totality in terms of the mechanics of sub-atomic reality or the eternal absolute, we are explaining totality in terms of general ideational motion engaged in history (like in the analysis of the physics community). Thus, we are interested in a totality capable of helping us understand how frames of reference and their conceptual transformations will be generally effected by scientific epistemology (artificial intelligence, genetic engineering, quantum computation, etc.). In this way, we seek to emphasize the hard work of an emergent unity or integration via collective historical processes of human individuation. Consequently, this theory of consciousness aims to elucidate a central dynamical narrative and value structure of being that is both grounded in cosmic evolution as a universal process (as emphasized in Part 2) and future-oriented towards a meaningful synthetical higher order level of ideational order (as emphasized in Part 3).

The first step in constructing a theory of consciousness with relevance to universal history is to situate our understanding within proper historical context. In order to move in this direction, let us first consider the main metaphysical systems of thought that have structured the history of philosophy. These main metaphysical systems of thought will be broadly classified from the Western perspective as ancient, modern, and deconstructionist metaphysics. In this general classification, we can say that ancient metaphysics structured the development of civilization in its predominantly agricultural phase; modern metaphysics structured the development of civilization in its predominantly industrial phase; and deconstructionist metaphysics has structured the development of civilization in its predominantly informational phase. Thus, these metaphysics represent the logical ideational substructure of civilization at different moments in the collective becoming of self-consciousness in universal history. 
In this analysis, we will pragmatically utilize the dynamical triadic structure of the imaginary-symbolic-real from Section 3 in order to situate our analysis of each major phase of Western civilizational metaphysics. Here, the imaginary as theoretical abstractions, the symbolic as enacted transformations and the real as concrete actualization in its general psychosocial manifestation are applied to different historical conceptions of unity. From all three phases, we can generalize the human mind as situated on the level of the symbolic order because self-consciousness is a narrative construct organized with a symbolic architecture capable of enacting historical transformations. However, what is considered imaginary (i.e., a theoretical abstraction) and real (i.e., a concrete actualization) will fundamentally change in all three major movements of civilization from ancient to modern to deconstructionist:

The ancient metaphysical structure considers as 'real' the 'eternal ideal' or God, and considers as 'imaginary' the 'physical world' or nature. Consequently, in ancient metaphysics, we get philosophies built around the ideals of a transcendent supernature that is primary in constituting the physical world and primary in relation to the human mind. Thus, ancient metaphysical systems forward the hypothesis that human beings come from an eternal ideal superspace before birth, return to an ideal superspace after death and are structured-constrained by an ideal superspace during existential (sexual-personal-creative) development.

The modern metaphysical structure considers as 'real' the 'physical world' or nature, and considers as 'imaginary' the temporality of the ideal. Consequently, in modern metaphysics, we get philosophies built around the natural world governed by eternal physical laws and ideas that have no 'transcendental' reality outside of their constitution in history. Thus, modern metaphysical systems forward the hypothesis that human beings come from nature before birth, return to nature after death, and are structured-constrained by the laws of physics during existential (sexual-personal-creative) development.

The deconstructionist metaphysical structure considers as 'real' the 'secular power' structures of society, and considers as 'imaginary' the various possible interpretations of the 'physical world'. Consequently, in deconstructionist metaphysics, we get philosophies built around the negation of social systems that seek to totalize human existence and distort our relation to the natural world. Thus, deconstructionist metaphysical systems forward the hypothesis that human beings come from social systems, return to social systems after death and are structured-constrained by social systems during existential (sexual-personal-creative) development.

This broad analysis of metaphysical totality structures aims to situate consciousness as something that is constituted by the symbolic order and constantly re-structuring its transformative state of being in relation to different notions of what is an imaginary theoretical abstraction and what is the most real concrete actualization throughout its collective development in universal history. In the ancient real, we can say that what consciousness developed in relation to was fundamentally the power of the theological and the transcendental. In the modern real, we can say that what consciousness developed in relation to was fundamentally the power of the scientific and the natural. In the deconstructionist real, we can say that what consciousness developed in relation to was fundamentally the power of the social and the self-analytic. Thus, in all systems, we get fundamentally different notions of totality as eternal unity: transcendental ideality, physical laws, or secular power.

In ancient metaphysics, totality is already closed and complete in the ideal real of supernature or God of religion; in modern metaphysics, totality is already closed and complete in the material real of natural laws of physics; and in deconstructionist metaphysics, totality is already closed and complete as a multiplicity of systems of social power (all of which represent different relativistic totalities). However, all of these metaphysical systems are unable to account for a totality where conscious reality is constituted by multiple observers becoming in asymmetrical temporal relation to ideal-real attractors independent of a transcendent superspace, physical laws or secular power. In other words, they fail to account for the general imaginary-symbolic-real triad in its own historical motion, which transcends 
the ancient, modern, and deconstructionist forms. Thus, for a conscious real on the level of universal history visions of totality related to a transcendental superspace, physical laws, or secular power all become a part of the same dynamical and general conscious real structuring the becoming of open and incomplete individuating observers searching for the truth of being in a unified eternal structure.

In this way, the most real, or the most concrete actualization, is an absence of 'something' that emerges because of and depending on symbolic observers' enacted transformations in history. This brings us towards a potential to formulate a theory of consciousness that can approach the real in-itself as an absence of something that emerges internal to the realm of symbolic observers. This formulation will attempt to structure a transmodern metaphysics derived from the dynamical motion of the general imaginary-symbolic-real structures (Figure 12). In a transmodern metaphysics, we aim to both synthesize historical forms of totality and approach technological singularity from an individuated perspective as an emergent unity produced as a general consequence of subject-object division. This would potentially allow us to construct a central narrative and value structure of being for consciousness. Here, narrative architectures represent a symbolical temporalization of eternity (beginning to end); and value structures represent an attempt to stabilize an emergent unity as a perfect circle capable of completing and closing in on itself.

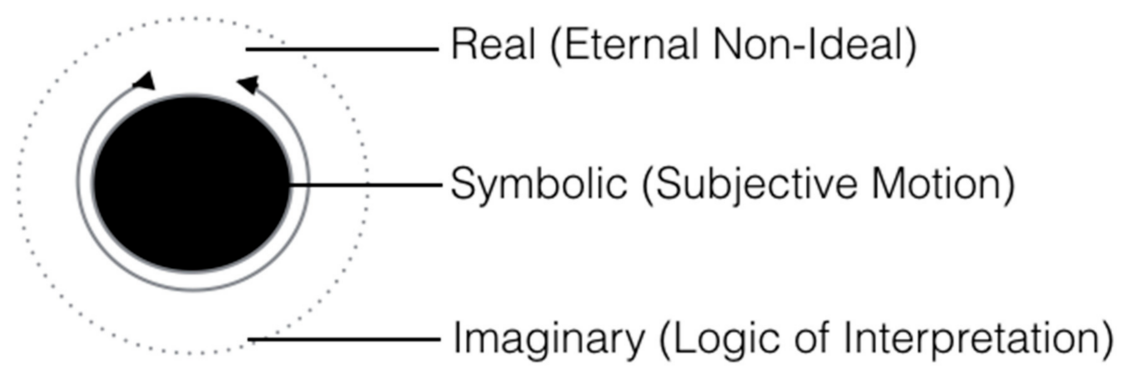

Figure 12. Transmodern totality. We represent a transmodern totality where the general motion of the human mind as symbolic emerges from the physical world as imaginary and starts to circulate around its own emergent desire for internal unity as real. The consequence of this general motion deployed in historicity produces a multiplicity of unities such as transcendental superspaces, physical laws, and secular power that stand in as paradoxical somethings where the real as a closed and completed circular is absent or impossible. In this sense all historical forms of the eternal real should ultimately be deconstructed on the level of external positing. However, all external positing of an eternal real ultimately emerge because of self-alienation as they represent the eternal real that emerges internal to the subject. In this way we find a real that is a multiplicity of unities internal to each individuated observer. Thus, the transmodern real offers the view that each subject is capable of creating its own world out of its own individuated symbolic transformations. Here the transcendental superspace, physical laws, and secular power all disappear as ultimately historical fictions on the level of specular images.

In terms of the synthesis of historical forms of totality, the transmodern real conceives of all particular cultural reals as unified conscious visions necessary for the structure of historical becoming. For example, the vision of a transcendental superspace of eternal ideality structures the objective ancient becoming of religious and philosophical intersubjectivity; the vision of physical laws structures the objective modern becoming of scientific and naturalist intersubjectivity; and the vision of secular power structures the objective deconstructionist becoming of social and activist intersubjectivity. Thus, different forms of intersubjective objectivity emerged and became necessary in different phases of civilization from the agricultural level stabilized by the intersubjective objectivity of God and Imaginary Faith; the industrial level stabilized by the intersubjective objectivity of Science and Rational Empiricism; and the informational level stabilized by the intersubjective objectivity of the Social and Critical Deconstruction. Of course, these are not the only historical forms of eternal ideality that have 
appeared on the transcendental horizon, but they are a few of the major and general reals that have structured intersubjective objectivity.

Thus, in terms of a transmodern metaphysics approaching the technological singularity we must not conceive of totality in terms of an eternally unified field, but instead as an eternally divided field between subject-object. As discussed this field produces individuated observers asymmetrically imbalanced in a duality universally structuring a general internal desire for unity expressing itself as a pure multiplicity of conscious visions. Here we build on the aforementioned idea that totality on the side of the subject is order-dreams-goals-presences; and totality on the side of the object is chaos-obstacles-challenges-absences. In this dualistic relation unities like a transcendental superspace, physical laws, or secular power represent intersubjective reals as 'points of impossibility' unconsciously posited by self-consciousness to resolve the far-from-equilibrium imbalance of dualistic becoming. Such reconciliation of far-from-equilibrium imbalance follows such logics as 'if we all believe in [faith, empiricism, deconstruction] we will be saved by [religion, science, society]'.

However, in terms of the transmodern real in-itself such unities as 'points of impossibility' are radically open to taking any form that an observer can maintain intersubjectively across its process of becoming as an objective reality. Furthermore, any externally imposed collectivist notion of an intersubjective objectivity will by necessity fail to approach the real of individuated becoming of a multiplicity of observers on the pathway to singularity. This is because the real as an impossibility emerges primordially in relation to divisions introduced by each subject's transformations (as opposed to preceding the subject's transformations). Thus, when we think of the real from the inside out (from the side of the subject) these points of impossibility structure a geometric curvature in a topographical state space. For example, a subject engaged in theological or philosophical transformations may conclude that the highest form of objective reality is a unified space of ideality (God); a subject engaged in scientific or naturalist transformations may conclude that the highest form of objective reality is a unified space of natural laws (Spacetime); a subject engaged in social or activist transformations may conclude that the highest form of objective reality is a unified space of secular power (State).

In all such social historical manifestations what is posited by self-consciousness is an objective real that exists before and after the subject's transformations or interventions into the real as an absolute background dependence. Thus, the historical subject tends to reify an object that it believes existed before it, and believes will exist after it (i.e., God, Spacetime, State). However, what the transmodern metaphysics introduces is the generality of a dynamical and open background that is overdetermined by the subject's own work motion. In this way the static-fixed background of transcendental ideality, physical laws, and secular power are conceived of as absolute only in relation to the subject's self-positing. This means ultimately that the real in a transmodern sense does not exist before and after the subject's own individuated becoming. As already emphasized the real in a transmodern sense is something that emerges and depends on the symbolic observers enacted transformations in history.

Thus, this transmodern metaphysics can approach technological singularity in an open and incomplete metaphysics to be determined by symbolic observers. In this approach it is posited that totality is nothing but a multiplicity of observers that circumambulate around an absent central unity appearing in an emergent intersubjective space constituted by individuated relations. In other words this is a real truth where each individuated unit of transformative identity is capable of producing an objectively recognized historical real as a pure difference or division via epistemological knowledge structures. These knowledge structures can retroactively change the nature of ontological being itself towards a higher connection or unity (as in the introduction of the symbolic forms of ancient, modern, and postmodern metaphysics throughout historical becoming). Consequently, on the approach to technological singularity, a transmodern metaphysics would predict the breakdown of historical visions of unified totality, and the consequent emergence of ever greater numbers of novel divisions that produce ever greater numbers of novel unities. The totality of divisions may represent the logical 
consequence of the becoming of the concept in universal history capable of producing a meta-level of unity inaccessible to any one consciousness but which is one consciousness in-itself.

To summarize the transmodern approach to both the historical synthesis of historical forms of totality and the individuated technological singularity let us consider this structure of totality in terms of divisions that introduce new unities. The ancient metaphysical system became a historical real through the pure division of religious and philosophical thinkers in Mesopotamia, Egypt, and Greece which allowed for the formation of a higher unity of transcendental ideality that objectively structured the intersubjective becoming of early agricultural societies for millennia. The modern metaphysical system became a historical real through the pure division of scientific and naturalist thinkers in Europe which allowed for the formation of a higher unity of physical laws that objectively structured the intersubjective becoming of early industrial societies for centuries. The postmodern metaphysical system became a historical real through the pure division of social and philosophical thinkers in Europe and North America which allowed for the formation of a higher unity of deconstructing secular power that objectively structured the intersubjective becoming of early information age societies for decades. Now in the transmodern world in-itself this same force of pure division is predicted to be expressed in increasingly distributed forms (independent of transcendental superspace, physical laws, and secular power) allowing for, perhaps, a higher proliferation of unities than ever before in human history.

In order to connect this notion of metaphysical totality built around emergent subject-object division aiming for unity with cosmic evolutionary philosophy as representing one unified ordering force we may frame it as a potential 'third path' to quantum gravity. Here the nature of a division is a depths where the subject appears as a quantum mechanical entity; and the nature of a unity is a height where the object appears as a gravitationally relativistic entity. In this third path to quantum gravity the real as truth of being is structured by multiple observers each with an attractor dependent horizon that attempts to form an eternal unity in its becoming. Consequently, this path becomes structured by multiple observers inside the universe as opposed to taking a structure of multiple universes as understood by one mythical observer outside the universe, as in quantum multiverse speculations [104]. Thus, instead of attempting to explain the primordial unity of the universe with recourse to a multiverse of infinite physical universes, we need only include the virtual potentiality and actual tendencies of human observers (a multiverse of observers). In this way the primordial astrophysical singularity where all being is one unity could meet technological singularity by way of the demands for unity by an observational multiplicity. Here cosmic evolutionary philosophy as a universal dynamic ideational motion emerges requiring dialectical analysis gives the appearance of a totality structured by an open-incomplete 4-dimensional sphere aiming for closure-completion.

Finally, this transmodern metaphysics as a theory of consciousness may allow us to approach the technological singularity in a novel way by understanding how epistemological constructs of general humanity become a fundamental part of ontological being. In terms of a human subject-oriented approach to technological singularity capable of reconciling our de-centered cosmic position we should emphasize that when we include the future actuality of artificial intelligence, genetic engineering, and quantum computing, we open up a totally new possibility space for observationally constituted dynamical action. In other words, this theory of consciousness requires us to include the future real of knowledge as an activity into the ontology of being as opposed to continuing to focus on an imaginary knowledge that passively reflects the real ontology of being. The consequences of such a perspectival shift forces us to confront the fact that although meaning does exist outside of the symbolic order out in the cosmos, meaning does have a concrete materiality within the symbolic order signaling orientation to higher unity.

In order to work towards being able to think such a reality we should start with the philosophical foundation. The possibility of including the future real of human knowledge as an activity into the fundamental ontology of being was formally opened with modern philosophical idealism and the identification of the a priori conceptual frame as a horizon of being [105]. Towards understanding how this fuller understanding of the relation between human knowledge and natural being itself manifests 
today we may draw an analogy related to modern physics. In modern physics there is a fundamental shift that has been occurring in high theory from desiring to know 'what the fundamental eternal laws of the physical universe are' to desiring to know 'why does the universe have the particular set of eternal physical laws that it does?' [106]. In order to properly resolve this fundamental shift in ontological questioning we must be capable of a perspective shift within physics itself that appreciates the ontological meaning of quantum computer theory [107], and the consequences of future quantum computation [108]. Here we have a form of fundamental physics knowledge which suggests that observers inside the universe can make an object with their knowledge structures (i.e., supercomputer) that can simulate any physical process (i.e., a physical universe).

The radicality of such a possibility as it relates to technological singularity cannot be understated, but how can we make a division capable of motivating future research in this direction? Here I will make a conjecture that when we are thinking totality from the perspective of subject-object division aimed at unity we need to make sense of fundamental ontological problems related to historical forms of totality. To be specific there appears still unresolved problems in science and mathematics as to both the fundamental natures of mathematical ideality and physical law. From the perspective of ancient metaphysics mathematical ideality exists in a transcendental superspace from eternity; and from the perspective of modern metaphysics physical laws exist in a natural space from eternity. Of course, most contemporary theorists are skeptical of both conjectures, even if both assumptions structure much of science and mathematics. For example, consider that science is often embedded in space and time as universal organizing categories, and mathematics is often perceived to represent a universal knowledge independent of context and history.

In the fundamentally emergentist transmodern totality we may be able to reconcile both problems by positing that mathematical ideality and physical law could be a part of an eternal loop or sphere where physical law emerge (astrophysical singularity; big bang) as a sensual background for observers to construct logical mathematical ideality; and observers constructing logical mathematical ideality emerge as a background capable of constituting sensual physical law (technological singularity). Indeed, is not a fundamental problem in quantum gravity the fact that 'eternal' physical laws of spacetime break down at the singularity of the big bang and the singularity of black holes? In this way, by including the multiplicity of individuating observers approaching technological singularity with their own loops of sense and logic, we may be able to reconcile the breakdown of laws and the constitution of new laws in one transmodern metaphysical system. From this perspective history is fundamentally structured by an observationally constituted expansion of freedom independent of spacetime coordinates that is predicted to result in an objectivity overdetermined by observers (Figure 13).

In this transmodern theory of consciousness, we must be capable of thinking how an individuated observer dividing being with a higher unity [109] could possibly by responsible for the generation of physical law [59] via the immanence of higher order technological possibility spaces constituted by ideational curvature $[34,110]$. Perhaps this is a way to understand the meaning of quantum computation on the level of fundamental physics and universal history where the physical laws themselves can become radically other via ideal manipulations. Thus, what this division suggests for a higher unity is precisely that researchers interested in understanding totality must take seriously a conscious totality that is divided between subject-object. The reconciliation of such a division requires the emergence of a qualitative phase transition where observers can themselves actively constitute the object-in-question as opposed to merely reflecting given being. In this sense, the dialectical approach to technological singularity is concerned with the way in which historically engaged individuated observers become central to future theories of totality. 


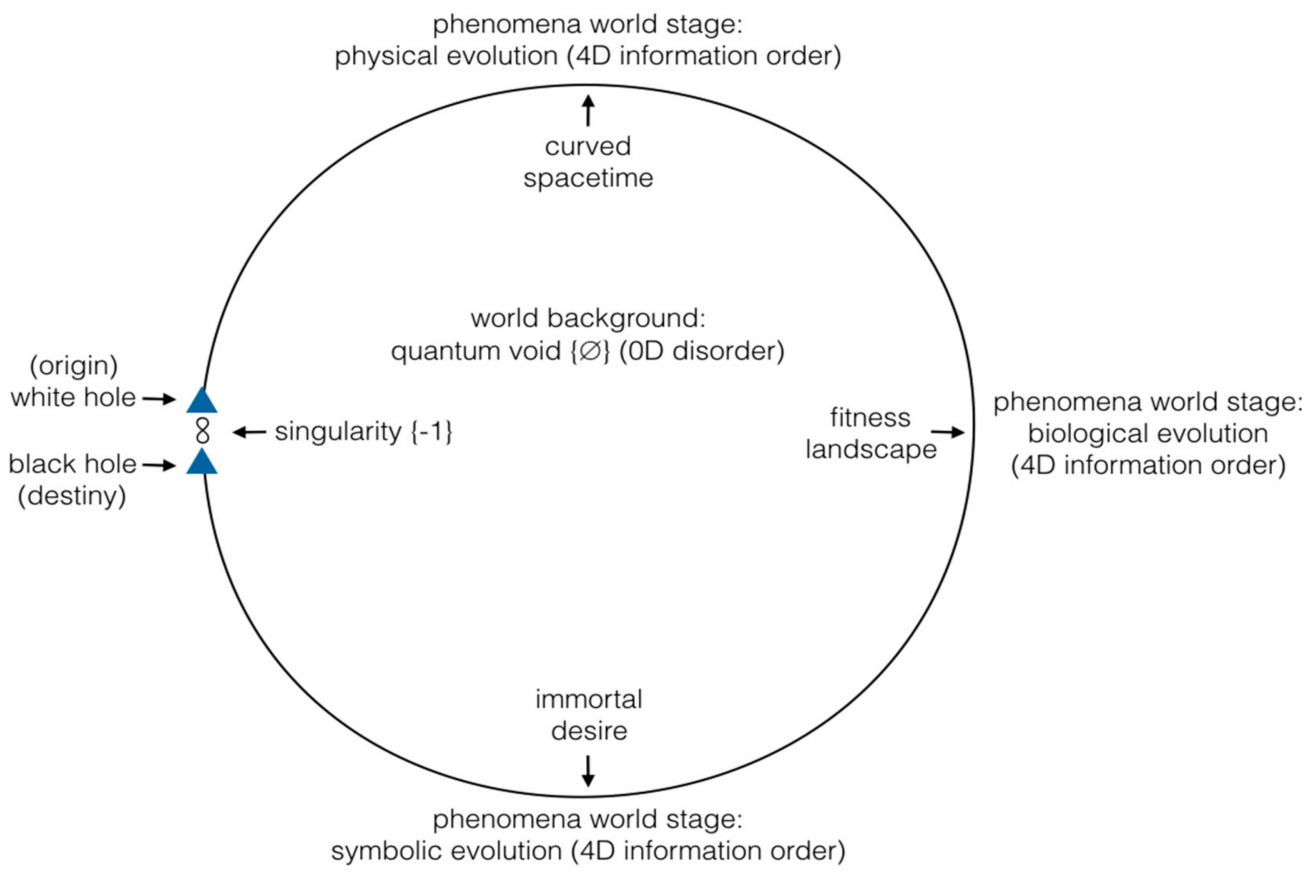

Figure 13. Cosmic evolution and dialectic connecting beginning and end. In this representation, we see the contemporary cosmic evolutionary process that can be divided between physical evolution of curved spacetime, biological evolution of fitness landscapes, and symbolic evolution of immortal desire. Here, although highly speculative, we can start to entertain a potential theoretical link between the mystery of the ordered astrophysical singularity at the beginning of spacetime and the mystery of the destiny of ordered evolutionary processes. From this link, we are asked to think the way in which the horizon of ideation can be possibly inscribed into the immanence of cosmic-physical processes via the inclusion of a type of extreme primordial and emergent curvature where evolutionary change can be reconciled with eternity. The true question here becomes the ultimate nature of the 'eternity'. Here, it is negativized $(-1)$ as absent in the historical process since its presence would nihilate our $4 \mathrm{D}$ existence. However, the possibility of the actualizing and perceiving higher super-symmetrical dimensions is mathematically real and experientially realizable given the known future technological possibility space available to future observers.

Conflicts of Interest: The authors declare no conflict of interest. The founding sponsors had no role in the design of the study; in the collection, analyses, or interpretation of data; in the writing of the manuscript, and in the decision to publish the results.

\section{References}

1. Heylighen, F. Complexity and Evolution: Fundamental Concepts of a New Scientific Worldview. Lecture Notes 2014-15. 2014, p. 30. Available online: http:/ / pespmc1.vub.ac.be/books/Complexity-Evolution.pdf (accessed on 31 May 2017).

2. Christian, D. What is Big History? J. Big Hist. 2017, 1, 4-19. [CrossRef]

3. Polchinski, J. String Theory: Volume 2, Superstring Theory and Beyond; Cambridge University Press: Cambridge, UK, 1998.

4. Russell, S.J.; Norvig, P. Artificial Intelligence: A Modern Approach; Prentice-Hall: Upper Saddle River, NJ, USA, 1995.

5. Carr, P.A.; Church, G.M. Genome engineering. Nat. Biotechnol. 2009, 27, 1151-1162. [CrossRef] [PubMed]

6. Last, C. Big Historical Foundations for Deep Future Speculations: Cosmic Evolution, Atechnogenesis, and Technocultural Civilization. Found. Sci. 2017, 22, 39-124. [CrossRef]

7. Verelst, K. Concerning the ontology of the World-Tree. In Visions on Nature-Comparative Studies on the Theory of Gaia and Culture; Elders, F., Ed.; VUB Press: Brussel, Belgium, 2004; pp. 96-122.

8. Sloterdijk, P. Spheres. Volume 1: Bubbles (Microspherology); Semiotext(e): Los Angeles, CA, USA, 2011. 
9. Weinert, F. Copernicus, Darwin and Freud: Revolutions in the History and Philosophy of Science; Wiley-Blackwell: Hoboken, NJ, USA, 2009.

10. Vidal, C. The Beginning and the End: The Meaning of Life in a Cosmological Context; Springer: Berlin, Germany, 2014.

11. Kojève, A. Introduction to the Reading of Hegel: Lectures on the Phenomenology of Spirit; Cornell University Press: Ithaca, NY, USA, 1980.

12. Koyré, A. From the Closed World to the Infinite Universe; Library of Alexandria: Alexandria Governorate, Egypt, 1957.

13. Turchin, V. The Phenomenon of Science: A Cybernetic Approach to Human Evolution; Columbia University Press: New York, NY, USA, 1977.

14. Vinge, V. The coming technological singularity. Whole Earth Rev. 1993, 81, 88-95.

15. More, M.; Vita-More, N. Part VIII-Future Trajectories Singularity. In The Transhumanist Reader; More, M., Vita-More, N., Eds.; Wiley-Blackwell: Hoboken, NJ, USA, 2013; pp. 361-363.

16. Vinge, V. Technological Singularity. In The Transhumanist Reader; More, M., Vita-More, N., Eds.; Wiley-Blackwell: Hoboken, NJ, USA, 2013; pp. 365-375.

17. Soares, N.; Fallenstein, B. Agent Foundations for Aligning Machine Intelligence with Human Interests: A Technical Research Agenda. In The Technological Singularity: Managing the Journey; Callaghan, V., Miller, J., Yampolskiy, R., Armstrong, S., Eds.; Springer: Berlin, Germany, 2017; pp. 103-126.

18. Moore, G. Cramming more components onto integrated circuits. Electronics 1965, 38, 1-4. [CrossRef]

19. Moore, G. Progress in digital integrated electronics. Available online: https://www.eng.auburn.edu/ agrawvd/COURSE/E7770_Spr07/READ/Gordon_Moore_1975_Speech.pdf (accessed on 5 April 2018).

20. Kurzweil, R. The law of accelerating returns. Available online: http://www.kurzweilai.net/the-law-ofaccelerating-returns (accessed on 5 April 2018).

21. Kurzweil, R. The Singularity Is Near: When Humans Transcend Biology; Penguin: London, UK, 2005.

22. Sirius, R.U.; Cornell, J. Transcendence: The Disinformation Encyclopedia of Transhumanism and the Singularity; Disinformation Books: New York, NY, USA, 2015.

23. Hanson, R. The Age of Em: Work, Love and Life When Robots Rule the Earth; Oxford University Press: Oxford, UK, 2016.

24. Goertzel, B.; Goertzel, T. (Eds.) The End of the Beginning: Life, Society, and Economy on the Brink of Singularity. Humanity + Press: San Jose, CA, USA, 2015.

25. Ulam, S. Tribe to John von Neumann. Bull. Am. Math. Soc. 1958, 64, 1-49. [CrossRef]

26. Good, I.J. Speculations concerning the first ultraintelligent machine. Adv. Comput. 1965, 6, 31-83.

27. Lenartowicz, M. Creatures of the semiosphere: A problematic third party in the 'humans plus technology' cognitive architecture of the future global superintelligence. Technol. Forecast. Soc. Chang. 2017, 114, 35-42. [CrossRef]

28. Zalasiewicz, J.; Williams, M.; Smith, A.; Barry, T.L.; Coe, A.L.; Bown, P.R.; Brenchley, P.; Cantrill, D.; Gale, A.; Gibbard, P.; et al. Are we now living in the Anthropocene? GSA Today 2008, 18, 4-8. [CrossRef]

29. Wark, M. General Intellects: Twenty-One Thinkers for the Twenty-First Century; Verso: London, UK, 2017.

30. Barrat, J. Our Final Invention: Artificial Intelligence and the End of the Human Era; St. Martin's Press: New York, NY, USA, 2013.

31. Bostrom, N. Superintelligence: Paths, Dangers, Strategies; Oxford University Press: Oxford, UK, 2014.

32. Nicolelis, M.; Cicurel, R. The Relativistic Brain: How It Works and Why It Cannot be Simulated by a Turing Machine; Kios Press: Sao Paulo, Brazil, 2015.

33. Kaku, M. The Future of the Mind: The Scientific Quest to Understand and Empower the Mind; Anchor Books: New York, NY, USA, 2014.

34. Smith, H.; Marranca, R. The World's Religions; Harper One: New York, NY, USA, 2009.

35. Wolfson, H.A.; Fackenheim, E.L. Philo: Foundations of Religious Philosophy in Judaism, Christianity, and Islam. Rev. Metaphys. 1947, 1, 89.

36. Mercer, C.; Trothen, T.J. (Eds.) Religion and Transhumanism: The Unknown Future of Human Enhancement; Praeger: London, UK, 2015.

37. Hughes, J. The politics of transhumanism and the techno-millennial imagination, 1626-2030. Zygon 2012, 47, 757-776. [CrossRef] 
38. Wolyniak, J. “The Relief of Man's Estate”: Transhumanism, the Baconian Project, and the Theological Impetus for Material Salvation. In Religion and Transhumanism: The Unknown Future of Human Enhancement; Mercer, C., Trothen, T.J., Eds.; Praeger: London, UK, 2015; pp. 53-70.

39. Pross, A.; Pascal, R. The origin of life: What we know, what we can know, and what we will never know. Open Biol. 2013, 3, 120190. [CrossRef] [PubMed]

40. Thompson, E. Mind in Life: Biology, Phenomenology, and the Sciences of Mind; Harvard University Press: Cambridge, MA, USA, 2002.

41. Dunbar, R. Why only humans have language. In The Prehistory of Language; Botcha, R., Knight, C., Eds.; Oxford University Press: Oxford, UK, 2009; pp. 1-26.

42. Chesterton, G.K. The Everlasting Man. 1925. Available online: http://www.gkc.org.uk/gkc/books/ everlasting_man.pdf (accessed on 5 January 2018).

43. Hegel, G.W.F. Phenomenology of Spirit; Miller, A.V.; Findlay, J.N., Translators; Motilal Banarsidass Publishers: Delhi, India, 1998.

44. Christian, D. Maps of Time: An Introduction to Big History; Berkeley University Press: Berkeley, CA, USA, 2004.

45. Kurzweil, R. The Singularity Is Near: When Humans Transcend Biology; Penguin: London, UK, 2005; p. 28.

46. Stewart, J. The Meaning of Life in a Developing Universe. Found. Sci. 2010, 15, 395-409. [CrossRef]

47. Heylighen, F. Self-organization of complex, intelligent systems. Available online: http://134.184.131.111/ papers /ECCO-paradigm.pdf (accessed on 5 January 2018).

48. Spier, F. Big History and the Future of Humanity; Wiley Blackwell: Hoboken, NJ, USA, 2015.

49. Spier, F. How big history works: Energy flows and the rise and demise of complexity. Soc. Evol. Hist. 2005, 4, 87-135.

50. Chaisson, E. Cosmic Evolution: The Rise of Complexity in Nature; Harvard University Press: Cambridge, MA, USA, 2001.

51. Smart, J. Evo Devo Universe? A Framework for Speculations on Cosmic Culture. In Cosmos and Culture: Cultural Evolution in a Cosmic Context; Dick, S.J., Lupisella, M.L., Eds.; Govt Printing Office, NASA SP-2009-4802; Govt Printing Office: Washington, DC, USA, 2008.

52. Stewart, J. The direction of evolution: The rise of cooperative organization. Biosystems 2014, 123, $27-36$. [CrossRef] [PubMed]

53. Kauffman, S.A. The origins of order: Self-organization and selection in evolution. In Spin Glasses and Biology; World Scientific: Singapore, 1992; pp. 61-100.

54. Heylighen, F.; Beigi, S.; Veloz, T. Chemical Organization Theory as a modelling framework for self-organization, autopoiesis and resilience. Available online: https://pdfs.semanticscholar.org/e9ff/ 09b77597f8c0499a3ef4de126e29687cc713.pdf (accessed on 2 January 2018).

55. Veitas, V.; Weinbaum, D. A world of views: A world of interacting post-human intelligences. In The Beginning and the End: Life, Society, and Economy on the Brink of Singularity; Goertzel, B., Goertzel, T., Eds.; Humanity + Press: San Jose, CA, USA, 2015; pp. 495-567.

56. Vidal, C. The Beginning and the End: The Meaning of Life in a Cosmological Context; Springer: Berlin, Germany, 2014; p. ix.

57. Krauss, L. A Universe from Nothing: Why There Is Something Rather than Nothing; Free Press: New York, NY, USA, 2012.

58. Aunger, R. Major transitions in 'big history'. Technol. Forecast. Soc. Chang. 2007, 74, 1137-1163. [CrossRef]

59. Von Bertalanffy, L. General System Theory: Foundation, Development, Applications; G. Braziller: New York, NY, USA, 1968.

60. Weaver, W. Science and Complexity. Am. Sci. 1948, 36, 536-544. [PubMed]

61. Heylighen, F. Complexity and Evolution: Fundamental Concepts of a New Scientific Worldview. Lecture Notes 2014-15. 2014, pp. 55-57. Available online: http:/ / pespmc1.vub.ac.be/books/Complexity-Evolution.pdf (accessed on 31 May 2017).

62. Rovelli, C.; Vidotto, F. Covariant Loop Quantum Gravity: An Elementary Introduction to Quantum Gravity and Spinfoam Theory; Cambridge University Press: Cambridge, UK, 2015.

63. Latour, B. An Introduction to Actor-Network Theory; Oxford University Press: Oxford, UK, 2005.

64. DeLanda, M. Intensive Science and Virtual Philosophy; Bloomsbury: Hong Kong, China, 2013; p. 59.

65. Carroll, B.W.; Ostlie, D.A. An Introduction to Modern Astrophysics; Cambridge University Press: Cambridge, UK, 2017. 
66. Corning, P. The Re-Emergence of "Emergence". Complexity 2002, 7, 18-30. [CrossRef]

67. Lineweaver, C.H.; Davies, P.C.W.; Ruse, M. Complexity and the Arrow of Time; Cambridge University Press: Cambridge, UK, 2013.

68. Smolin, L. Time Reborn; Houghton Mifflin Harcourt: Boston, MA, USA, 2013.

69. Zeh, H.D. The Physical Basis of the Direction of Time; Springer: New York, NY, USA, 1990.

70. Aunger, R. A rigorous periodization of 'big' history. Technol. Forecast. Soc. Chang. 2007, 74, 1164-1178. [CrossRef]

71. Prigogine, I.; Stengers, I. Order out of Chaos: Man's New Dialogue with Nature; Bantam Books: New York, NY, USA, 1984.

72. DeLanda, M. Intensive Science and Virtual Philosophy; Bloomsbury: Hong Kong, China, 2013; p. 65.

73. Weinbaum, D.R. Complexity and the Philosophy of Becoming. Found. Sci. 2015, 20, 283-322. [CrossRef]

74. Žižek, S. Less Than Nothing: Hegel and the Shadow of Dialectical Materialism; Verso: London, UK, 2012.

75. Heylighen, F. Return to Eden? Promises and perils on the road to global superintelligence. In The Beginning and the End: Life, Society, and Economy on the Brink of Singularity; Goertzel, B., Goertzel, T., Eds.; Humanity + Press: San Jose, CA, USA, 2015.

76. Kyriazis, M. Systems neuroscience in focus: From the human brain to the global brain? Front. Syst. Neurosci. 2015, 9. [CrossRef] [PubMed]

77. Husserl, E. The Crisis of European Sciences and Transcendental Phenomenology: An Introduction to Phenomenological Philosophy; Northwestern University Press: Evanston, IL, USA, 1970.

78. Hawkins, J.; Blakeslee, S. On Intelligence: How a New Understanding of the Brain Will Lead to the Creation of Truly Intelligent Machines; Macmillan: Basingstoke, UK, 2007.

79. Heylighen, F. Life Is an Adventure: An Agent-Based Reconciliation of Narrative and Scientific Worldviews. Available online: http:/ / pespmc1.vub.ac.be/Papers/Life-Adventure.pdf (accessed on 4 October 2017).

80. Adams, F.; Laughlin, G. The Five Ages of the Universe: Inside the Physics of Eternity; The Free Press: New York, NY, USA, 1999.

81. Deacon, T. Incomplete Nature: How Mind Emerged from Matter; W.W. Norton and Company: New York, NY, USA, 2011.

82. Žižek, S. Less Than Nothing: Hegel and the Shadow of Dialectical Materialism; Verso: London, UK, $2012 ;$ pp. 3-5.

83. Lenartowicz, M.; Weinbaum, D.R.; Braathen, P. Social systems: Complex adaptive loci of cognition. Emerg. Complex. Organ. 2016, 18. [CrossRef]

84. Plato, R.E. The Dialogues of Plato: Volume II: The Symposium; Translated with Comment by Allen, R.E.; Yale University Press: London, UK, 1998.

85. Lacan, J. Knowledge and truth. In The Seminar of Jacques Lacan. Book XX: On Feminine Sexuality, The Limits of Love and Knowledge, 1972-73; Jacques-Alain, M., Ed.; Translated with Notes by Bruce Fink; W.W. Norton and Company: New York, NY, USA, 1999; p. 90.

86. Žižek, S. Absolute Recoil: Towards a New Foundation of Dialectical Materialism; Verso: London, UK, $2014 ;$ p. 255.

87. Belfiore, F. The Triadic Structure of the Mind: Outlines of a Philosophical System; University Press of America: Lanham, MD, USA, 2014.

88. Stasheff, J. From operads to 'physically' inspired theories. In Operads: Proceedings of Renaissance Conferences; American Mathematical Soc.: Providence, RI, USA, 1997; Volume 202, pp. 53-82.

89. Forcey, S.; Springfield, D. Geometric combinatorial algebras: Cyclohedron and simplex. J. Algebraic Comb. 2010, 32, 597-627. [CrossRef]

90. Evans, D. An Introductory Dictionary of Lacanian Psychoanalysis; Routledge: London, UK, 2006; p. 1.

91. Peterson, J.B. Maps of Meaning: The Architecture of Belief; Routledge: New York, NY, USA, 1999; pp. 332,334.

92. Žižek, S. Less Than Nothing: Hegel and the Shadow of Dialectical Materialism; Verso: London, UK, 2012; p. 17.

93. Heylighen, F. Complexity and Evolution: Fundamental Concepts of a New Scientific Worldview. Lecture Notes 2014-15. 2014, p. 139. Available online: http://pespmc1.vub.ac.be/books/Complexity-Evolution.pdf (accessed on 31 May 2017).

94. Hegel, G.W.F. The Science of Logic; Cambridge University Press: Cambridge, UK, 2010.

95. Kurzweil, R. How my predictions are faring. Kurzweil AI 2010, 1-146.

96. Kurzweil, R. How to Create a Mind: The Secret of Human thought Revealed; Penguin: New York, NY, USA, 2012.

97. Jameson, F. The Valences of the Dialectic; London: Verso, 2009.

98. Evans, D. An Introductory Dictionary of Lacanian Psychoanalysis; Routledge: London, UK, 2006; p. 187. 
99. Smolin, L. Three Roads to Quantum Gravity; Basic Books: New York, NY, USA, 2001; pp. 9-10.

100. Penrose, R. The Road to Reality: A Complete Guide to the Laws of the Universe; A.A. Knopf: New York, NY, USA, 2004; p. 1018.

101. Frolov, V.P.; Zelnikov, A. Introduction to Black Hole Physics; Oxford University Press: Oxford, UK, 2011 ; p. 340.

102. Zagzebski, L. The Two Greatest Ideas. KU Leuven University, Centre for Logic and Analytic Philosophy, 2017. Available online: https:/ / hiw.kuleuven.be/claw/events/agenda/kardinaal-mercier-lecture-lindazagzebski-the-two-greatest-ideas (accessed on 22 October 2017).

103. Smolin, L. Three Roads to Quantum Gravity; Basic Books: New York, NY, USA, 2001; p. 10.

104. Smolin, L. Three Roads to Quantum Gravity; Basic Books: New York, NY, USA, 2001; p. 48.

105. Žižek, S. Less Than Nothing: Hegel and the Shadow of Dialectical Materialism; Verso: London, UK, 2012; p. 9.

106. Smolin, L. Three Roads to Quantum Gravity; Basic Books: New York, NY, USA, 2001.

107. Deutsch, D. Quantum theory, the Church-Turing principle and the universal quantum computer. Proc. R. Soc. Lond. A Math. Phys. Eng. Sci. 1985, 400, 97-117. [CrossRef]

108. Lloyd, S. Programming the Universe: A Quantum Computer Scientist Takes on the Cosmos; Knopf: New York, NY, USA, 2006.

109. Penrose, R. The Road to Reality: A Complete Guide to the Laws of the Universe; A.A. Knopf: New York, NY, USA, 2004.

110. Drexler, E. Radical Abundance: How a Revolution in Nanotechnology Will Change Civilization; Public Affairs: New York, NY, USA, 2013.

(C) 2018 by the author. Licensee MDPI, Basel, Switzerland. This article is an open access article distributed under the terms and conditions of the Creative Commons Attribution (CC BY) license (http:/ / creativecommons.org/licenses/by/4.0/). 